\title{
CAPT ACTP
}
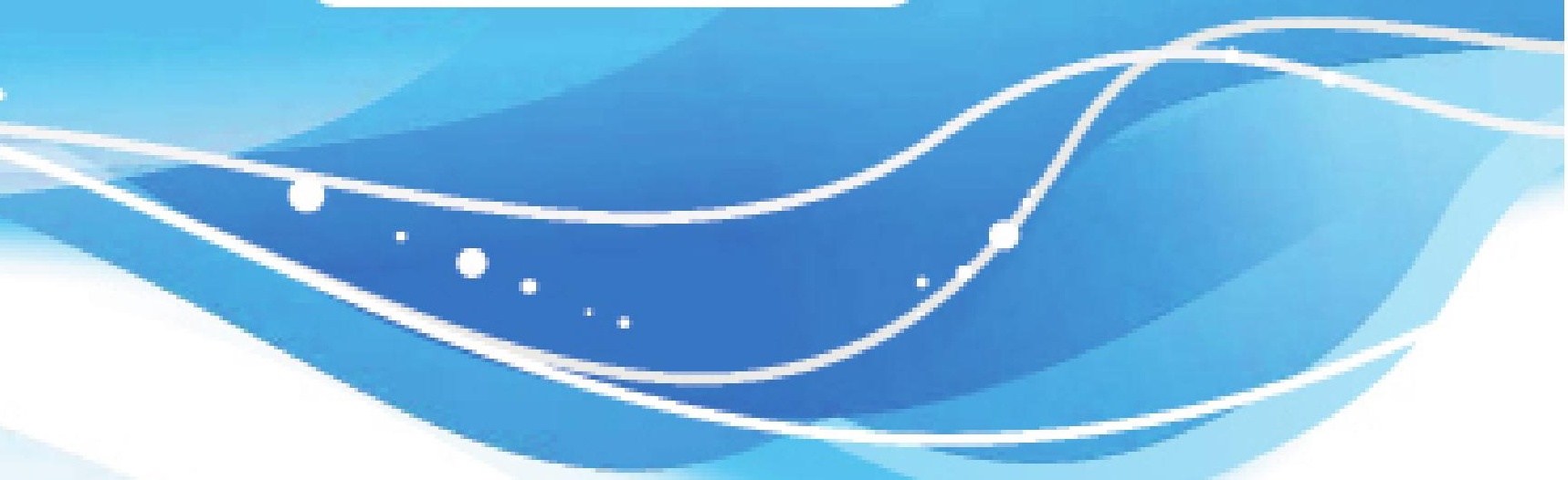

The Canadian Association for Population Therapeutics I Association Canadienne pour la Thérapeutique des Populations presents:

\section{Managing Risk to Improve Health Outcomes: How to Move Population Health Forward in an Era of Uncertainty \\ ABSTRACTS \\ October $26^{\text {st }}-27^{\text {nd }}, 2020$ \\ Virtual}

\begin{abstract}
s are published on-line in The Journal of Population Therapeutics and Clinical Pharmacology www.jptcp.com
\end{abstract}


1. Non-steroidal anti-inflammatory drug use does not adhere to prescribing guidelines for older men or women with dementia

Trenaman SC ${ }^{1}$, Bowles $\mathrm{SK}^{1,2}$, Kirkland $\mathrm{S}^{1}$, Andrew $\mathrm{MK}^{1,2}$

${ }^{1}$ Dalhousie University, ${ }^{2}$ Nova Scotia

Health Authority shanna.trenaman@dal.ca

Abstract: Older adults with dementia experience pain, which is a potential contributor to their responsive behaviours. One option for pain treatment is non-steroidal anti-inflammatory drugs (NSAIDs). Best practice guidelines for prescribing in older adults recommend that if NSAIDs are used, use should be short-term (less than 90 days), indomethacin should be avoided and two or more NSAIDs should not be used at a time. The objective of the present study was to complete a drug utilization review, with attention to prescribing guidelines, and a sex-based analysis of NSAID use in older adults with dementia in Nova Scotia, Canada.

We examined NSAID use in a cohort of adults aged 65 years and older with dementia in Nova Scotia, Canada. Prescription data was examined from April 1, 2010 to March 31, 2015. Concordance with prescribing guidelines was compared for men and women using descriptive statistics. Analyses used unadjusted odds ratios and t-tests as appropriate.

Our cohort contained 30,703 older adults with dementia over the period of study $(17,988 \quad(58.6 \%)$ female and
10,573 (34.4\%) male) of whom 6,199 received at least one prescription for an NSAID. NSAID use showed no sex difference $(3,741$ (60.3\%) female and 1,850 (29.8\%) male (OR 0.95, 95\% Cl [0.89-1.03]). Duration of use was longer in women than in men (274.4 days versus 237.4 days, $p=0.005$ ), though notably the duration of use for both men and women exceeded the recommendation for less than 90 days. This occurred in more than 30\% of NSAID users. Indomethacin was used by 474 older adults with dementia in the cohort (1.3\%) with higher use in males (OR $\quad 0.46, \quad 95 \% \quad \mathrm{Cl} \quad[0.38-0.56]$ ). Concurrent NSAID use was found in 130 older adults with dementia (76 female and 44 male) with no sex difference (OR $0.7795 \% \mathrm{Cl}$ [0.51-1.23]). While NSAID use was similar in men and women, the duration of use was longer in women. Interventions to reduce NSAID use for older adults with dementia are needed.

2. Psychiatric and non-psychiatric polypharmacy among older adults with schizophrenia: a populationbased study in Quebec, Canada, between 2000 and 2016

Sirois $C^{4}$, Lunghi $C^{1}$, Ouali $A^{2}$, Rochette $L^{3}$ ${ }^{1}$ Department des sciences de la santé, University du Quebec, ${ }^{2}$ Faculte de Medicine, Universite Laval, Quebec, ${ }^{3}$ Institut national de sante publique du Quebec, ${ }^{4}$ Faculte de Pharmacie, Universite Laval, Quebec; Centre d'excellence sur le vieillissement de Quebec, Canada caroline.sirois@pha.ulaval.ca

Background: Schizophrenia is a severe psychiatric disorder associated with an increased risk of type 2 diabetes,

\section{J Popul Ther Clin Pharmacol Vol 27(4):e19-e54; December 1, 2020.}

This article is distributed under the terms of the Creative CommonsAttribution-Non Commercial 4.0 International License. 
dyslipidemia and obesity. As adults with schizophrenia age, they become at high risk for multimorbidity and polypharmacy. However, little is known about the trends in total medication use within this population. The objective of this study was to draw a portrait of polypharmacy among Quebec older adults with schizophrenia from 2000 to 2016.

Methods: This population-based cohort study used the data of the Quebec Integrated Chronic Disease Surveillance System of the National Institute of Public Health of Quebec to characterize recent trends and patterns of medications use, according to age and sex. We identified all Quebec residents over 65 years with an ICD-9 or ICD-10 diagnosis of schizophrenia. We calculated the total number of medications used by every individual in each year under study, and the age- and sex-standardized proportions of individuals with polypharmacy (10+ medications, 15+, and 20+). We further identified the clinical and socio-demographic factors associated with polypharmacy using Poisson regression models with robust variance estimation.

Results: From 2000 to 2016, the prevalence of total medication used increased across all age groups, with a median of 8 medications used in 2000, which rose to 11 in 2016. The agestandardized proportion of individuals exposed to different definitions of polypharmacy also increased over time: 10+ medications: $36.9 \%$ to $62.2 \%$; $15+$ : $13.3 \%$ to $34.4 \%$; $20+: 3.9 \%$ to $14.4 \%$. In the multivariate regression, the only clinically significant factor associated with polypharmacy was the number of comorbidities (e.g., Polypharmacy-10+: RR[2 VS 0-1]=1.57; 95\% IC:1.51-1.65). Conclusions: This study shows a noticeable increase in polypharmacy exposure of older adults with schizophrenia in recent years, raising concerns about the growing risks for adverse effects and drug interactions.

\section{Polypharmacy among older adults in Quebec between 2000 and 2016 \\ Sirois C, Gosselin E, Simard M, Dube M Universite Laval, Institut national de sante publique du Quebec caroline.sirois@pha.ulaval.ca}

Context: The aging of the population leads to an increase in the prevalence of chronic diseases and multimorbidity. These conditions favor polypharmacy, the use of several medications in the same individual. Although polypharmacy is associated with undesirable health events, there is little population-based data to monitor its evolution. The purpose of this study is to describe the use of medications among older adults in Quebec between 2000 and 2016. Methods: We used the Quebec Integrated Chronic Disease Surveillance System, which combines five medico-administrative files. We included individuals over the age of 65 living in community and insured by the public drug plan (approximately 90\% of the population). For each year between 2000 and 2016, and for each individual, we calculated the number of different medications claimed. We assessed the proportion of individuals using at least 5, 10 and 15 different medications per year by standardizing for age.

Results: The average number of medications per individual increased from 6.8 (SD: 5.3) to 8.7 (6.2) between 2000 and 2016. The standardized proportion of individuals using at

J Popul Ther Clin Pharmacol Vol 27(4):e19-e54; December 1, 2020.

This article is distributed under the terms of the Creative Commons Attribution-Non Commercial 4.0 International License. (C) 2020 CAPT. 
least 5 medications per year increased from $62 \%$ to $73 \%$ during the same period. The proportions of users of at least 10 and at least 15 medications increased from $26 \%$ to $38 \%$ and from $9 \%$ to $16 \%$ respectively.

Conclusion: The prevalence of polypharmacy among older adults in Quebec is high. Polypharmacy indicators incorporating a quality component could prove useful in assessing potential health outcomes of polypharmacy.

4. Multimorbidity occurs 5 to 10 years sooner in highly deprived neighbourhoods

Marc S, Marjolaine D, Caroline S Laval University, Quebec, Canada, National public health Institute, Quebec, Canada marc.simard@inspq.qc.ca

Context: Multimorbidity, the cooccurrence of at least two chronic diseases, is a growing public health challenge in industrialized countries.

The objective of this study is to quantify the effect of socioeconomic status on the occurrence of multimorbidity. Methods: We performed a populationbased study using the Quebec Integrated Chronic Disease Surveillance System, a registry combining claims data, hospital records and demographic information on more than $95 \%$ of the adult population in the province of Quebec, Canada. We defined multimorbidity as the presence of at least two diseases from a list of 31 chronic diseases included in a validated index. We assessed the number of diseases in a 5year window before April 1, 2017 for each individual 25 years and older. We assessed socioeconomic status using the material deprivation index, a validated measure that assigns a deprivation quintile based on place of residence. Neighbourhoods with the most deprived quintile have the lowest mean income, employment rate and education level.

Results: The prevalence of multimorbidity increases with age (25-29 years: 5\%; 80 years and older: 60\%) and is higher in deprived neighbourhoods (e.g. 60-64 years: $20 \%$ in lowest deprived quintile vs $26 \%$ in highest). Multimorbidity occurs at a younger age in disadvantaged areas. The $5 \%$ multimorbidity prevalence observed in 25-29 years of age living in highest deprived neighbourhood is similar to that observed in 40-44 year of age in the lowest deprived neighbourhood. This suggests multimorbidity could occur at least 10 years earlier for people living in highest deprived neighbourhoods. The gap narrows with age (55-59 years: 7 years; 70-74 year: 4 years). Discussion I Conclusion: Socioeconomic status may influence the age at which multimorbidity occurs, since multimorbidity can appear up to 10 years earlier in people living in most deprived neighbourhoods. Actions to prevent chronic diseases and promote healthy lifestyles must be intensified in deprived areas. 
5. Disease activity trajectories for early and established rheumatoid arthritis: data from a rheumatoid arthritis cohort

Movahedi M, Cesta A, Li X, Bombardier $\mathrm{C}$ and other $\mathrm{OBRI}$ investigators Toronto Genera Hospital Research Institute, University Health Network, Toronto, ON mmovahed@uhnres.utoronto.ca

Background: Description of disease activity status in patients with rheumatoid arthritis (RA) at fixed points in time modelled as continuous (e.g. number of swollen joints counts), dichotomous variable (e.g. remission or low disease status using composite measures) do not reflect the patients disease course in chronic and relapsing RA.

Objectives: We proposed to describe the longitudinal disease activity trajectories for patients with early and established RA over two years follow-up in routine clinical care.

Methods: RA patients enrolled in the Ontario Best Practices Research Initiative (OBRI) with available DAS28ESR over two years of follow-up were included. Using a latent growth curve modelling (LCGM), subgroups of patients following distinct pattern of DAS28-ESR change over time were identified. Model selection was based on Bayesian information criterion (BIC). Results: A total of 1273 patients were included, 454 (36\%) with early RA and 819 (64\%) with established RA. At baseline, patients with early RA were significantly younger (57.3 vs. 59.1 years) and with higher DAS28-ESR (4.6 vs. 4.3), and were less likely to have an erosion $(25.0 \%$ vs. $59.7 \%)$, to be RFpositive $(70.3 \%$ vs. $76.8 \%)$, and to use biologic DMARDs (7.0\% vs. $29.2 \%)$. In patients with early RA (Figure 1A), three subgroups of patients were identified by LCGM with a better fit (BIC: -3070.84). Almost $88 \%$ patients with moderate disease activity reached remission (group 1: $48.4 \%$ ) or low disease status (group 2: $39.3 \%$ ) at year 2 , while $12 \%$ of patients with high disease profile remained in a moderate state (group 3). In patients with established RA (Figure 1B), seven subgroup of patients were identified by LCGM with a better fit (BIC: -5378.13). After 2 years follow-up, $37.5 \%$ of patients in remission or low disease state at baseline remained or reached to remission (group 1 and 2, respectively). Only 17.3\% of patients with high disease activity at baseline reached remission (group 5). $16.5 \%$ patients with high disease activity at baseline remained in high disease status at year 2 (group 4 and 6). Two other group of patients (group 3 and 7) with moderate or high disease activity at baseline remained in a moderate state after two years.

Conclusion: Disease course is different between early and established RA. While $70 \%$ of early RA patients with moderate or high disease profiles reached remission, only $17 \%$ of established patients with high disease activity achieved remission after 2 years of follow-up. These findings suggest the potential effects of receiving early treatment and health care. The impact of sociodemographic, clinical and medication profile on disease course will be examined as future work for this study.

J Popul Ther Clin Pharmacol Vol 27(4):e19-e54; December 1, 2020.

This article is distributed under the terms of the Creative CommonsAttribution-Non Commercial 4.0 International License. (C) 2020 CAPT. 
6. Sociodemographic, disease, and medication profile of RA patients under 65 years compared with 65 years or older at registry enrollment:

Data from a rheumatoid arthritis cohort

Movahedi M, Cesta A, Li X, Bombardier $\mathrm{C}$ and other OBRI investigators Toronto General Hospital Research Institute mmovahed@uhnres.utoronto.ca

Background: Age is an important factor that can affect disease course, physical function and treat to target strategy for patients with rheumatoid arthritis (RA). We aimed to describe sociodemographic, disease and medication profile of patients with RA in the Ontario Best Practices Research Initiative (OBRI) by their assigned age group at time of their enrollment. Methods: RA patients enrolled in the OBRI between 1st Jan 2008 and 31st Dec 2019 were included. Patients were allocated into two age groups, under 65 years and 65 years or older. Descriptive cross sectional analysis was used to compare sociodemographic characteristics (gender, ethnicity, spoken language, education, health insurance, and smoking status), disease activity [28 tender and swollen joint count (28SJC and 28TJC), physician global assessment (PhGA), clinical disease activity index (CDAI)], patient report outcomes (PROs) including patient global assessment (PtGA), fatigue score, global pain, and HAQ-DI, and medication profile (prior use of cSDMARDs, prior use of bDMARDs, using new bDMARDs or cSDMARDs) between the two age groups at enrollment. We calculated the standardized difference as the difference in means or proportions divided by the standard error. A significant difference between the two groups was defined as an absolute value greater than 0.10 .

Results: A total of 3,734 patients were included; 2562 (68.5\%) were under 65 yeras old and 1172 (31.5\%) were 65 years or older. Sociodemographic profile: Patients under 65 years were significantly more likely to be female (79.7 vs. $73.5 \%$ ), non-caucasian (14.4 vs. $7.4 \%)$, current smokers (18.8 vs $9.3 \%$ and have post-secondary education (62.6 vs. 44.6\%), and more likely to have private health insurance (75 vs. 49\%) and report English as their spoken language (7.0 vs $9.8 \%$ ). Disease activity and PROs profile: Patients under 65 years were significantly more likely to be antiCCP positive (63.0 vs. $57.5 \%$ ), report higher PtGA (mean: 4.8 vs. 4.5 ), higher global pain (mean 4.8 vs. 4.4), higher fatigue score (mean 5.0 vs. 4.6), and lower HAQ-DI (mean 1.1 vs. 1.2).

No other significant differences were found between the two age groups. In terms of presence of comorbidities, patients under 65 years had significantly lower proportions of hypertension, cardiovascular disease, diabetes mellitus, lung disease, gastrointestinal disease and malignancy. However, interestingly this group of patients had a higher proportion of depression $(17.8 \%$ vs $13.3 \%)$.

Medication profile: At enrollment, patients under 65 years were significantly more likely to have used prior bDMARDs (31.4 vs.26.1\%), and were more likely to be starting a new bDMARD $(17.1$ vs. $12.8 \%)$, or csDMARDs $(38.6$ vs. $35.6 \%)$. No difference in prior use of csDMARDs was found between the two groups.

J Popul Ther Clin Pharmacol Vol 27(4):e19-e54; December 1, 2020.

This article is distributed under the terms of the Creative CommonsAttribution-Non Commercial 4.0 International License.

(C) 2020 CAPT. 
Conclusions: In this real world data descriptive study, we found that disease activity measures were similar in patients under 65 years compared to those 65 years or older. However, sociodemographics, PROs, comorbidities, and medication profiles were different between two groups. These differences should be taken into account for any clinical decision toward outcome improvement in patients.

\section{The impact of continuity of care} on medication adherence

Yao S1, Lix L², Teare $\mathrm{G}^{3}$, Evans $\mathrm{C}^{1}$, Blackburn $\mathrm{D}^{1}$

${ }^{1}$ College of pharmacy and nutrition, University of Saskatchewan, 2Department of community health science, faculty of medicine, University of Manitoba, ${ }^{3}$ Alberta Health Services. shy516@mail.usask.ca

Objectives: Continuity of care (COC) is considered an important determinant of medication adherence based on measures such as the usual provider continuity index (UPCI) that are derived exclusively from physician visit claims. This study aimed to: a) determine if high UPCI values predict physicians who deliver different clinical services; and b) compare UPCI with an integrated COC measure in a multivariable model of patients receiving statin medications. Methods: This was a retrospective cohort study of new statin users between 2012 and 2017 in Saskatchewan, Canada. We calculated sensitivity/ specificity of a high UPCI value for predicting physicians who were prescribers of statins and/or providers of complete medical examinations. Next, we used logistic regression models to test two measures of COC (high UPCI value or an integrated COC measure) on the outcome of optimal statin adherence (proportion of days covered $\geq 80 \%$ ). The DeLong test was used to compare predictive performance of the two models.

Results: Among 55,144 new statin users, a high UPCI was neither a sensitive or specific marker of physicians who prescribed statins or performed a complete medical exam. The integrated COC measure had a stronger association with optimal adherence (adjusted odds ratio [OR] $=1.56,95 \%$ confidence interval [Cl] 1.50 to 1.63) than UPCI (adjusted OR $=1.23,95 \% \mathrm{Cl}$ 1.19 to 1.28), and improved predictive performance of the adherence model.

Conclusion: The number of physician visits alone appears to be insufficient to represent COC. An integrated measure improves predictive performance for optimal medication adherence in patients initiating statins.

8. Health Utilities Index Mark 3 Scores for Children: Population norms for Canada based on the 1994-95

National Longitudinal Survey of Children and Youth

Humphries $\mathbf{B}^{\mathbf{1}}$, Guertin JR ${ }^{2,3}$, Feeny $\mathrm{D}^{4,5,6}$, Tarride $\mathrm{JE}^{1,4,6,7}$

${ }^{1}$ Department of Health Research Methods, Evidence and Impact, McMaster University, ${ }^{2}$ Department of Social and Preventive Medicine, Universite Laval, ${ }^{3}$ Centre de recherche du CHU de Quebec âe Universite Laval, Axe Sante des Populations et Pratiques Optimales en Sante, ${ }^{4}$ Department of Economics, McMaster University, ${ }^{5}$ Health Utilities Incorporated, ${ }^{6}$ Centre for Health Economics and Policy Analysis (CHEPA), McMaster University, 
${ }^{7}$ McMaster Chair in Health Technology

Management, McMaster University humphrib@mcmaster.ca

Background: Utility scores are an important tool for evaluating healthrelated quality of life. Utility score norms have been published for Canadian adults yet there are no nationally representative utility score norms available for children under the age of 12 years.

Methods: We used data from the 19941995 National Longitudinal Survey of Children and Youth to provide utility score norms for Canadian children ages 4 to 11 years. Utility scores were estimated using the Health Utilities Index Mark 3 (HUI3) instrument and were reported as weighted average (95\% confidence intervals[Cl]) and median values. Utility scores were stratified by sociodemographic and medical characteristics of the person most knowledgeable (PMK) and child. Regression analyses were used to identify predictors of utility scores. All results were weighted using sampling weights provided by Statistics Canada. Results: Among the 3,125,996 children in the weighted sample, the average utility score was $0.97(95 \% \mathrm{Cl} 0.97-0.97)$. Most children (65.75\%) had a utility score of 1.00 indicating Perfect health. Clinically and statistically significant lower utility scores were observed among children for whom the presence of epilepsy, cerebral palsy, kidney condition or disease, mental handicap, learning disability, and emotional, psychological or nervous difficulties were reported.

Conclusions: This study provides utility score estimates based on a nationally representative sample of Canadian children. While the majority of Canadian children have a utility score indicating Perfect health, certain chronic conditions were associated with lower utility scores. Further research examining the severity of chronic conditions and children's utility scores is warranted.

9. Public versus private payer perspective: Implications on costeffectiveness

OReilly $\mathbf{D J}^{1}$, Lavoie $\mathrm{R}^{2}$

${ }^{1}$ Pharmacy Consulting, Health Benefits and Payment Solutions, TELUS Health, Toronto, ON, Canada, ${ }^{2}$ Synergyx Consulting, Montreal, QC, Canada daria.oreilly@telus.com

Objective: The goal of this study was to evaluate the impact the perspective taken (i.e., private vs. public) has on the incremental cost-effectiveness ratio (ICER).

Methods: A retrospective review of 47 drug submissions was conducted. Reanalysis of the economic models included probabilistic sensitivity analyses to recalculate ICERs based on private payer perspective. The recalculated ICERs were compared using: 1) average difference in incremental cost per quality-adjusted life year (QALY); 2) absolute percent change in ICER; 3) difference in ICER for oncology vs. non-oncology medications.

Results: A total of 34 products were included in the analysis, representing 47 indications (31 in oncology with the number of indications ranging from 1-5 per product). $\hat{A}$ Versus the public payer perspective, the average difference in ICER when adopting a private payer perspective was an increase of $\$ 8,188$ / QALY (SD \$53,782; $95 \% \quad \mathrm{Cl}[-$ $\$ 97,225,+\$ 113,600])$. Â The mean

J Popul Ther Clin Pharmacol Vol 27(4):e19-e54; December 1, 2020.

This article is distributed under the terms of the Creative CommonsAttribution-Non Commercial 4.0 International License. (C) 2020 CAPT. 
absolute percent change was $2 \%$ (SD $14 \%$; $95 \%$ Cl $[-29 \%$ to $+25 \%]$ ) for oncology medications. There was an average decrease of $\$ 5,409 / \mathrm{QALY}$ for oncology medications and an increase of $\$ 50,338 / Q A L Y$ for non-oncology medications when the private payer perspective was used.

Conclusion: Adopting a private payer perspective increased the ICER by $\$ 8,188$ with an increase of only $2 \%$ on average, however the high $14 \%$ standard deviation suggests that the difference can be large in either direction. The high uncertainty highlights the importance of conducting the analysis from a private payer perspective.

10. Supporting stability for oncology patients in a time of health system instability: creation of an online hub for information, mental health and wellness and practical supports

Binder L, Tong R, Huang A

Save Your Skin Foundation louise.binder49@gmail.com

Background: COVID-19 has created healthcare systems disruptions and isolation for people living with cancer, resulting in the need for (1) easily accessible information about government and patient group programs (2) mental wellness supports and (3) practical supports (e.g. taxi program, grocery delivery, digital connectivity). Notwithstanding serious resource constraints, patient groups teamed up to fill these gaps by creating an online hub - launched May 6, 2020.

Methods: Patient surveys were conducted that identified these needs. We validated the results with oncology groups and the All.Can Canada Steering Committee including doctors, researchers, industry members and health systems experts. A leadership team, including a project coordinator, and working groups were established. The former raised funds, sourced services and coordinated the project. The latter, each led by a Chair, and supported by volunteers, guided content for the three areas. Media and webinars supplemented direct email and social media campaigns to promote the hub. Results: Our task force is made up of 14 national oncology groups. 100 new links and resources have been added since launch. Over 250 taxi requests have been fulfilled in Toronto and Montreal. We have 1000 newsletter subscriptions and a cumulative total of 17,000 page views and 10,000 sessions by 7000 users. We launched our hub in French in August and now $40 \%$ of our traffic is from Quebec.

\section{Conclusions:}

1. COVID-19 exacerbated already existing healthcare system gaps, requiring enhanced patient support.

2. Patient groups filled these gaps.

3. These supports will be adapted to support needs that will persist beyond COVID-19.

4. This program is limited to supporting patients with access to technology.

\section{Making value-based agreements a reality in Canada through RWE}

Glennie $\mathbf{J}^{5}$, Cheung $\mathbf{W},{ }^{1}$ Stein $B^{2}$, Bouchard $\mathrm{S}^{3}$, Cheema $\mathrm{P}^{4}$

${ }^{1}$ University of Calgary, Alberta Health

Services, Oncology Outcomes, ${ }^{2}$ Colorectal Cancer Canada, ${ }^{3}$ NESSS, ${ }^{4}$ William Osler Health System, University of Toronto, 5 J.L. Glennie Consulting Inc. judith_glennie@on.aibn.com

J Popul Ther Clin Pharmacol Vol 27(4):e19-e54; December 1, 2020.

This article is distributed under the terms of the Creative CommonsAttribution-Non Commercial 4.0 International License. (C) 2020 CAPT. 
Payer, academic, clinician, and patient group perspectives will be critical in making real-world evidence (RWE) frameworks for value-based agreements a reality in Canada.

There is much discussion about the potential for RWE generation to address clinical and/or economic uncertainties in Canadian health technology assessment (HTA) recommendations. Despite this, there is no consensus on how to operationalize RWE in reimbursement decision making and no agreed-to method for data collection to leverage RWE as part of value-based agreements (VBA).

Payers across Canada acknowledge that ongoing data collection through RWE approaches would address clinical and economic uncertainty. To support such approaches, most provinces have data infrastructure that facilitates RWE collection and assessment and have expressed interest in exploring potential pilot projects in individual jurisdictions. Barriers and gaps to leveraging RWE for VBAs are well characterized by all stakeholders: the lack of leadership to coordinate payer and clinical aspects of RWE implementation; need for clarity around data collection and governance; and, the significant capacity and resources required to deliver meaningful change.

There is a desire among stakeholders to overcome these barriers in Canada, as has already been accomplished in other countries. Fostering trust among

different stakeholders is of paramount importance and can be a realistic goal if all parties commit to transparency and shared goals of delivering innovation and improving patient outcomes.

Payers and industry can help to ensure
Canada does not fall behind and can do so by publishing a transparent framework in partnership with other stakeholders for RWE-based VBAs.

\section{Impact of Patented Medicine Prices Review Board new reference countries on drug prices in Canada: \\ A comparison of current and anticipated list prices for top drugs in the country \\ Langevin C \\ Universite de Montreal \\ chloe.langevin@umontreal.ca}

Objective: To assess the impact on list prices in Canada of modifying the basket of reference countries used by the Patented Medicine Prices Review Board (PMPRB)

Methods: Fifteen therapeutic classes were selected from the $2019 \mathrm{CIHI}$ report on prescribed drug spending in Canada in the category: Top drug classes by total program spending (TPS). Ontario list prices were used as Canadian prices for the analysis, and international prices were retrieved from each country's drug price platform. The estimated impact on list prices was calculated as the difference between current list prices and projected median international prices (MIP) under the new regime.

Results: 42 brand name drugs (100 DINs) still under the PMPRB's jurisdiction were analysed. Modifying the reference countries is expected to be associated with an overall weighted average list price reduction of $28.4 \%$. The greatest anticipated list price reduction is for Selective Serotonin Reuptake Inhibitors with an average of $68.4 \%$. In comparison, the smallest anticipated reduction is an average $0.7 \%$ for direct factor $\mathrm{Xa}$ inhibitors.

J Popul Ther Clin Pharmacol Vol 27(4):e19-e54; December 1, 2020.

This article is distributed under the terms of the Creative CommonsAttribution-Non Commercial 4.0 International License. 
Conclusions: List prices in Canada will significantly decrease as a result of the change in reference countries used by PMPRB. The weighted average price reduction required for the 42 brand name drugs included analysis is estimated at $28 \%$. Variability was observed across classes, but expected reductions are as high as $68 \%$. The analysis does not consider other measures included in the new regulations and, as such, likely underestimates the total anticipated impact of the reform on list prices in Canada.

\section{Comparing academic and community practices in the} management of rheumatoid arthritis: data from the OBRI registry

Hepworth $\mathbf{E}^{1}$, Mirza $\mathbf{R}^{2}$, Movahedi $\mathbf{M}^{3}$, Aydin $\mathrm{S}^{4}$, Cesta $\mathrm{A}^{3}$, Bombardier $\mathrm{C}^{3,5,6}$ ${ }^{1}$ University of Ottawa, ${ }^{2}$ University of Toronto, ${ }^{3}$ Toronto General Hospital Research Institute, University Health Network, Toronto, ON, ${ }^{4}$ Faculty of Medicine, Division of Rheumatology, University of Ottawa, the Ottawa Hospital Research Institute, Ottawa, Canada, ${ }^{5}$ Department of Medicine (DOM) and Institute of Health Policy, Management, and Evaluation (IHPME), University of Toronto, Toronto, ON, ${ }^{6}$ Division of Rheumatology, Mount Sinai Hospital, Toronto, ON.

reza.mirza@mail.utoronto.ca

Background: There is variation among rheumatologists in managing rheumatoid arthritis (RA) that bears on patient important outcomes. The treatto-target paradigm requires responsive treatment escalation to obtain low disease activity and prevent morbidity.
Advanced Therapy (bDMARD or tsDMARD) initiation requires time and effort on the part of the treating rheumatologist. Some academic centres, such as the Rheumatology Divisions at the Universities of Ottawa and Toronto employ Biologics Coordinators to manage the drug-funding application process. In many community practices, this falls on the rheumatologist. Given disparate resources, including access to trainees, we aimed to determine if time to Advanced Therapy (AT) initiation, or switch, in patients with moderate-high disease activity differed between community and academic practices in Ontario. We are not aware of any published comparison of RA management between academic and community practices.

Methods: We included adult patients enrolled in the Ontario Best Practices Research Initiative (OBRI) registry between 2008-2019 with at least 2 visits and 6 months of follow-up with moderate-high disease activity. Population A included those with at least 2 months of combined csDMARD therapy (either Methotrexate and Leflunomide; or Methotrexate, Sulfasalazine and Plaquenil) who ultimately started AT. Population B included those on any AT who ultimately switched AT. We used independent adjusted for age, sex, disease duration, and comorbidity cox proportional hazards models to compare academic and community settings in time from first recorded moderate-high disease activity to initiation, or switch in AT. We completed exploratory analyses to assess disease activity at the 3 visits prior to therapy change in all patients and between those started on bDMARDs and tsDMARDs. 
Results: Baseline characteristics were similar between community and academic settings in both population $A$ and $B$. The notable differences are swollen joint count and RA duration, which were 1 higher, and slightly longer in the academic group, respectively. There was no difference between community and academic settings in time to initiation or switch in AT before and after adjustment. In both settings, there was a significant delay in starting AT: on average 241 days following first moderate-severe disease activity while on combination csDMARDs. Across three visits leading up to therapy change, disease activity, and swollen joint count were high (mean CDAl: 24; mean SJC: 6.3). These were lower numerically for new tsDMARD starts (mean CDAl: 5.9; mean SJC: 1.8). Conclusion: Due to the study's small sample size and observational nature, conclusions drawn are limited. The data suggest no difference in time to initiation or switch of AT in response to moderatehigh disease activity between community and academic settings as hypothesized. Ontario Rheumatologists are allowing for significant delays during which disease is uncontrolled prior to initiating AT. We propose that paperwork burden may be contributing, thus we will next compare time to initiation of AT with and without Limited Use codes in those with active disease on combined csDMARDs.

14. Mental health in the workplace: The economic costs of productivity losses due to presenteeism and sickness absence in Canadian workers having psychological distress

Gilbert-Ouimet $\mathbf{M}^{1,2}$, Sultan-Taieb $\mathrm{H}^{3}$, Brisson C ${ }^{2,4}$, Guertin JR ${ }^{2,4}$
${ }^{1}$ Department of Health Sciences, Universite du Quebec, Rimouski, Levis, Canada, ${ }^{2}$ Population health and optimal health practices department, $\mathrm{CHU}$ research center FRQS of the $\mathrm{CHU}$ of Quebec City, Quebec, Canada, ${ }^{3}$ Department of organization and human resources, Universite du Quebec Ã Montreal (UQAM), ${ }^{4}$ Social and preventive medicine department, Laval University, Quebec City, Quebec, Canada.

mahee_gilbert-ouimet@uqar.ca

Introduction: The costs of productivity losses (i.e. presenteeism and sickness absence) associated specifically with mental health problems have yet to be evaluated in a Canadian context, specifically among older workers who tend to find themselves in more vulnerable work situations than their younger counterparts. We evaluated the average 12-month costs of presenteeism and sickness absences due to psychological distress (PD) among female and male white-collar workers aged 45 years and older in Quebec City, Canada.

Methods: Workers of the latest follow-up (2015-2018) of the Prospective Quebec Study on Work and Health were included in this cross-sectional study $(n=1472)$. PD, presenteeism and sickness absences were self-reported using validated questionnaires. Crude and adjusted generalized linear models were performed to examine the annual average costs of presenteeism and sickness absences per worker, across PD statuses.

Results: PD was associated with presenteeism (adjusted prevalence ratios (PR) of 1.31 [95\% Cl: $1.15-1.51]$ in women and $1.70[95 \% \mathrm{Cl}: 1.42-2.04]$ in men) and with sickness absence 
(1.69 [95\% Cl: 1.32-2.15] in women and 1.98 [95\% Cl: $1.42-2.76]$ in men). The average cost of presenteeism per worker was $3,353 \mathrm{C} \$$ and $6,663 \mathrm{C} \$$ higher among women and men having PD, respectively, compared to those without PD. The average cost of sickness absences per worker was $1,082 \mathrm{C} \$$ and $1,787 \mathrm{C} \$$ higher among women and men having $\mathrm{PD}$, respectively.

Conclusion: Primary prevention strategies aiming to reduce psychological distress might contribute to lower the economic burden associated with presenteeism and sickness absences in the Canadian workforce.

\section{Examining self-monitoring of blood glucose in the Nova Scotia public pharmacare program \\ Hillier TWR ${ }^{1}$, Giacomantonio ${ }^{2}$ \\ ${ }^{1}$ Department of Medicine, Dalhousie University, ${ }^{2}$ Division of Cardiology, Department of Medicine, Dalhousie University tr290997@dal.ca}

Background: Nova Scotia is one of the only remaining provinces lacking a blood glucose test strip limit for dependents of its provincial pharmacare plan with type 2 diabetes, despite research demonstrating their efficacy and cost effectiveness.

Objective: This study aimed to estimate potential cost savings to the Nova Scotia Public Pharmacare Program under multiple blood glucose test strip quantity limit models.

Methods: All blood glucose test strip claims submitted to the Nova Scotia
Provincial Pharmacare Program were ascertained for 2014-2017. Cost savings to the provincial pharmacare program were subsequently estimated for the years of study, as well as a 5-year period after the study. Cost savings based on two blood glucose test strip limit models were compared in analyses. Additionally, potential cost savings were estimated for patients with cardiovascular disease with indication for SGLT-2 inhibitors, or GLP1 agonists to demonstrate their potential efficacy in the Nova Scotian population.

Results: Blood glucose test strips for approximately 24,000 Nova Scotians were covered by the Nova Scotia Provincial Pharmacare program each year from 2014-2017. Blood glucose test strip quantity limits could have reduced reimbursements by $\$ 3-9.9$ million under the restriction models used. In the cardiovascular disease population specifically, reductions of between $\$ 618,880$ and $\$ 3,862,414$ could have been observed.

Conclusion: In addition to potentially reducing cardiovascular complications, the Nova Scotia healthcare system could save millions of dollars should blood glucose test strip limits be imposed on patients with type 2 diabetes who do not use agents associated with hypoglycemia such as sulfonylureas or insulin.

\section{Impact of the COVID-19 pandemic on chronic pain management: A web- based pan-Canadian study Lacasse $\mathbf{A}^{\mathbf{1}}$, Page $\mathrm{MG}^{2,3}$, Choiniere $M^{2,3}$, Dassieu $L^{2}$, Janelle-Montcalm $A^{2}$, Nguena Nguefack $\mathrm{HL}^{1}$, Godbout-Parent $\mathrm{M}^{1}$, Fauteux $\mathrm{C}^{4}$, Hudspith $\mathrm{M}^{5}$, Laliberte $\mathrm{J}^{4}$, Moor $\mathrm{G}^{5}$, Sutton $\mathrm{K}^{5}$, Thompson $\mathrm{J}^{6}$, Wilhelm $\mathrm{L}^{7}$}


1'Departement des sciences de la sante, Universite du Quebec en AbitibiTemiscamingue (UQAT), RouynNoranda, Quebec, Canada, ${ }^{2}$ Centre de recherche du Centre hospitalier de lâ Universite de Montreal (CRCHUM), Montreal, Quebec, Canada, ${ }^{3}$ Departement d'anesthesiologie et de medecine de la douleur, Faculte de medecine, Universite de Montreal, Montreal, Quebec, Canada, ${ }^{4}$ Association quebecoise de la douleur chronique (AQDC), Montreal, Quebec, Canada, ${ }^{5}$ Pain BC, Vancouver, British Columbia, Canada, ${ }^{6}$ Canadian Center of Excellence on Chronic Pain in Veterans, Hamilton, Ontario, Canada, ${ }^{7}$ Canadian Arthritis Patient Alliance, Halifax, Canada

Anais.Lacasse@uqat.ca

Background: Multimodal treatment is recognized as the best paradigm for chronic pain (CP) management. Careful balance between pharmacological and non-pharmacological approaches is thus desirable, but can easily be disrupted. This study aimed to explore the impact of the COVID-19 pandemic on pharmacological and nonpharmacological management of $\mathrm{CP}$. Methods: A pan-Canadian crosssectional study was conducted between April and May 2020 among adults living with CP. Participants completed a webbased questionnaire about changes in their pain treatment because of the pandemic, in addition to reasons for such changes.

Results: A total of 2864 participants shared their treatment experience (mean age: $49.74 \hat{A} \pm 13.69$ yrs, range: 18-99, women: $83.51 \%$ ). Among prescribed or over-the-counter pain medications users $(n=2533), 38.29 \%$ reported that they changed their pharmacological treatment. Main reasons were: 1) Change in pain symptoms, 2) Lack of access to prescribers/cancellation of medical appointments, and 3) Increase of medication intake to compensate for stopping non-pharmacological treatments. Among participants who used non-pharmacological pain management approaches $(n=2471)$, $68.19 \%$ reported that they modified their treatment because of the pandemic. Common reasons reported by participants were lack of access to clinics/exercise installations or the need to compensate for stopping another nonpharmacological treatment. Sociodemographic and clinical factors associated with such disruptions in pain treatment were also explored using multivariable regression models.

Conclusions: Our study underlines the negative impacts of the COVID-19 pandemic on access to pain relief, which is considered a fundamental human right. Results will inform the development of interventions in order to be better prepared for future crises.

\section{Can Canada's patient support program infrastructure support the collection of real-world data for use in outcomes-based agreements? Wills $\mathbf{A}^{1}$, De Jaray $A^{2}$, Dalseg $C^{3}$, Sze $\mathrm{F}^{4}$, Turnbull $\mathrm{G}^{5}$ ${ }^{1} 20$ Sense Corp, ${ }^{2}$ AstraZeneca Canada Inc, ${ }^{3}$ BioScript Solutions, ${ }^{4}$ Bayer Inc., ${ }^{5}$ Novartis Pharmaceuticals Canada Inc. awills@20sense.ca}

Background: The 2020 Real-World Evidence \&amp; Outcomes-Based Agreement Working Group is conducting research on the use and capabilities of

J Popul Ther Clin Pharmacol Vol 27(4):e19-e54; December 1, 2020.

This article is distributed under the terms of the Creative CommonsAttribution-Non Commercial 4.0 International License. 
patient support program (PSP) data in Canada, with the purpose of investigating the opportunity for PSP infrastructure use for the collection of real-world data to support outcomesbased agreements (OBA).

Methods: The Canadian PSP Data Capabilities Survey was conducted in July 2020 and consisted of 40 questions and to understand the baseline state of PSP data, PSP data capabilities, and future plans for PSP data collection as it pertains to generating RWD to support OBAs. Online surveys were completed by 59 respondents, including 15 pharmaceutical manufacturers (32 unique respondents), 10 PSP service providers (21 unique respondents), and

6 'other' respondents. Additional qualitative interviews were conducted with 9 companies. Survey themes included: [1] Infrastructure \& Data Collection, [2] Usability of Data (Quality and Capture Rate), [3] Data Usage, [4] Roadblocks \& Challenges, [5] Future Plans.

Results: Key findings include: [1] Broad data collection is occurring today within PSPs, including RWD. [2] PSP data are increasingly being leveraged for formal research and analyses. [3] Canadian stakeholders are gaining experience with PSP data use, and will continue to invest in PSP data capabilities and applications

Conclusions: Survey findings suggest that Canada's PSP infrastructure is readying itself to be able to support the collection of RWD for use in OBAs. The pace of evolution in PSP data sophistication, and the associated PSP infrastructure, is expected to increase, including the further development of capabilities to support OBAs.
18. Almost half of seniors initiating oral bisphosphonate therapy are exposed for 3 or more years understanding the benefits and harms of prolonged therapy is needed

Hayes KN1, He N², Brown KJ1,3,4, Cheung $A^{1,5}$, Juurlink $D N^{1,3,6}$, Cadarette $\mathrm{SM}^{1,2,3,7}$

${ }^{1}$ Dalla Lana School of Public Health, University of Toronto, Toronto, ON, Canada, ${ }^{2}$ Leslie Dan Faculty of Pharmacy, University of Toronto, Toronto, Ontario, Canada, ${ }^{3}$ ICES, Toronto, Ontario, Canada, ${ }^{4}$ Public Health Ontario, Toronto, ON, Canada, 5Toronto General Hospital Research Institute, Toronto, ON, Canada, ${ }^{6}$ Sunnybrook Research Institute, Toronto Ontario Canada, ${ }^{7}$ Eshelman School of Pharmacy, University of North Carolina, Chapel Hill, North Carolina, United States k.hayes@mail.utoronto.ca

Background: Oral bisphosphonates (alendronate and risedronate) are the primary drugs used to treat osteoporosis in Canada. Clinical guidelines recommend at least 3 years of bisphosphonate therapy to reduce fracture risk, yet rare but serious adverse events are associated with use $>5$ years. Our objective was to describe patterns of long-term ( $\geq 3$ years) oral bisphosphonate use.

Methods: We identified first oral bisphosphonate dispensation among adults aged $\geq 66$ years from $2000 / 11$ to $2016 / 12$, and followed them until death or $2019 / 12$ to identify patients with $\geq 3$ years of bisphosphonate use (proportion of days covered $\geq 80 \%$, using 3 -year rolling windows). 
Patterns of long-term use, medication switching patterns, and osteoporosis therapy gaps $\geq 120$ days among patients with long-term therapy were described.

Results: We identified 260,784 eligible seniors initiating bisphosphonate therapy in Ontario. Of these, $46 \% \quad(n=120,368)$ met criteria for long-term therapy, mean age $=75.0$ (SD 6.7) years, $80 \%$ women. The mean length of long-term therapy was 7.6 (SD 3.4) years for women and 6.7 (SD 3.0) years for men; $31 \%$ were treated for $\geq 5$ years. Twenty-percent experienced no gaps before long-term therapy, and $74 \%$ experienced a treatment gap after a median 5.3 years of therapy. Eighty-percent of those who returned to therapy after a gap reinitiated an oral bisphosphonate. Most patients without long-term therapy did not switch to other osteoporosis medications.

Conclusions: Almost half of patients initiating oral bisphosphonates are exposed long-term, with one-third treated for $\geq 5$ years. Benefits and harms of bisphosphonate therapy beyond 3 years are needed to inform the effects of longterm exposure.

\section{Statin initiation: Guideline concordance and characteristics of new users in Quebec, Canada}

Johnson SMA, Choiniere M, Bally M, Dube MP, Tardif JC, Gaudet D, Bergeron J, Lanctat $\mathrm{H}$, Lelorier J Centre de Recherche du Centre Hospitalier de lâ Universite de Montreal (CRCHUM), Montreal, Canada, Canadian Network of Observational Drug Effect Studies, Montreal, Canada sarasa.johnson@gmail.com
Statins are widely prescribed for the prevention of cardiovascular (CV) events. Our objective was to describe the characteristics of patients newly prescribed a statin by general practitioners and assess concordance of prescribing with national guidelines. Patients who were 18 years or older, French-speaking, available for the 2year study duration, and had no history of statin use were recruited. Biological parameters were measured, and medical history, sociodemographic characteristics and health behaviours were recorded using structured questionnaires. Patients' eligibility for a statin was assessed using the Canadian Cardiovascular Society's dyslipidemia guidelines. Of the 1631 new statin-users enrolled, $47.6 \%$ were women. Mean age for all patients was 57.4 years. According to the Canadian guidelines, $50.6 \%$ of patients were considered at high risk for a CV event or had a statin indicated condition. Moderate and low risk patients represented $26.7 \%$ and $22.7 \%$ of patients respectively.

\section{Access to zoledronic acid} through the public drug plan for seniors in Ontario

Konstantelos $\mathbf{N}^{1}, \operatorname{He} \mathbf{N}^{1,2}, \operatorname{Kim} \mathrm{S}^{1,3}$, Cheung $\mathrm{AM}^{1,4}$, Burden $\mathrm{AM}^{1,5}$, Grootendorst $\mathrm{P}^{1}$, Cadarette $\mathrm{SM}^{1,2}$ ${ }^{1}$ University of Toronto, Toronto, Ontario, Canada, ${ }^{2} \mathrm{CEES}$, Toronto, Ontario, Canada, ${ }^{3}$ Women's College Hospital, Toronto, Ontario, Canada, ${ }^{4}$ University Health Network, Toronto, Ontario, Canada, ${ }^{5}$ ETH Zurich, Switzerland n.konstantelos@mail.utoronto.ca

Background: Zoledronic acid (ZA) is an IV bisphosphonate dosed no sooner than yearly that became available through the Ontario Drug Benefit

J Popul Ther Clin Pharmacol Vol 27(4):e19-e54; December 1, 2020.

This article is distributed under the terms of the Creative CommonsAttribution-Non Commercial 4.0 International License. (C) 2020 CAPT. 
program under limited use (LU) to treat Pagets disease 2006/10/23, high risk postmenopausal osteoporosis 2012/08/27, and men at high risk for osteoporosis 2018/ $02 / 28$.

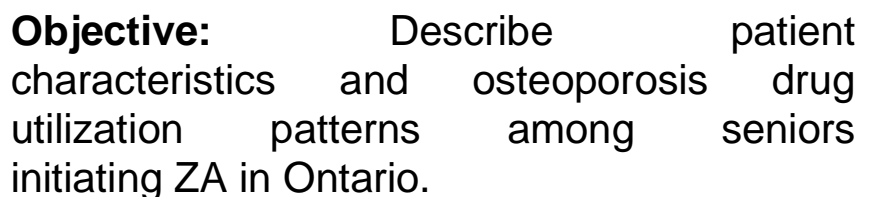

Methods: We identified residents aged â\%o $¥ 66$ years initiating ZA through to 2020/04 using the Ontario Drug Benefit database. Patient enrolment data were linked with medical and pharmacy claims to describe patient characteristics and identify future osteoporosis medication use.

Results: We identified 4,235 seniors $(82 \%$ women, mean age $=76.1$ years, $\mathrm{SD}=7.0$ ) initiating $\mathrm{ZA} ; 64 \%$ had a history of oral bisphosphonate, $8 \%$ denosumab, $7 \%$ raloxifene and $1 \%$ calcitonin therapy. Prior to 2012/08/27, all patients accessed ZA using the Pagets LU code, yet only 10\% had a diagnosis of Pagets disease. Broadening coverage to include patients at high risk for osteoporosis increased the mean monthly number of patients initiating ZA from 15 to 35 , yet $19 \%$ continued to indicate Pagets LU. Among 3,756 with â\%o $¥ 1.5$ years of follow-up, $46 \%$ received a single ZA dose, $30 \%$ switched to denosumab, and $12 \%$ switched to an oral bisphosphonate.

Conclusions: ZA is an important treatment option for osteoporosis, yet is not readily available. Pagets disease is rare and thus the validity of LU codes and use to treat Pagets disease is uncertain. Better access to ZA and understanding of benefits/safety by number of doses and sequential therapy is needed.
21. Utilization of hydroxychloroquine and azithromycin in Canada during the COVID-19 pandemic: experience from a large Canadian private payer

Penner N, Lu A, Lal A, Blouin J

Sun Life

nianda.penner@sunlife.com

Background: In March 2020, study results suggesting that hydroxychloroquine alone or in combination with azithromycin was associated with viral load reduction in COVID-19 patients received important media attention. Canadian pharmacists reported significant growth in the number of prescriptions issued for one or a combination of these two products. Professional associations released statements to warn their members on the potential safety risks of these medications, and the drug shortages that may impact patients taking these drugs for chronic diseases such as rheumatoid arthritis.

Objective: Determine if there was an increase in the volume of claims for hydroxychloroquine with or without azithromycin following media attention in March 2020.

Methods: Using Sun Life's drug claims database, all unique claimants of hydroxychloroquine with or without azithromycin were extracted, from January 2020 until April 2020. The claims in March and April 2019 were also extracted to serve as a historical baseline.

Results: In March 2020, there was a total of 6,383 claimants for hydroxychloroquine, of which 254 (4\%) also claimed azithromycin. This represented a 50\% increase in the volume of hydroxychloroquine claims compared to

J Popul Ther Clin Pharmacol Vol 27(4):e19-e54; December 1, 2020.

This article is distributed under the terms of the Creative CommonsAttribution-Non Commercial 4.0 International License. (C) 2020 CAPT. 
the number of claimants for both hydroxychloroquine and azithromycin compared to March 2019.

Conclusion: There was a significant spike in the number of individuals claiming hydroxychloroquine with or without azithromycin in March 2020. The number of claimants returned to historical levels in April 2020.

\section{Reimbursement Recommendations of Conditionally-Approved Cancer Drugs in Canada}

Arthur $\mathrm{E}^{1,2}$, Milenkovski $\mathbf{R}^{2}$, Ball $\mathrm{G}^{2}$, Marino $\mathbf{J P}^{2}$

${ }^{1}$ University of Guelph, ${ }^{2}$ Gilead Sciences

Canada Inc.

earthur@uoguelph.ca

Background: Health Canada's Notice of Compliance with Conditions (NOC/c) pathway is designed to facilitate early access to drugs that treat serious diseases with high unmet need, or which demonstrate a significant improvement in the benefit/risk profile relative to currentlyavailable therapies. Cancer therapies must also have their clinical and health economic evidence evaluated by the pan-Canadian Oncology Drug Review (pCODR) to receive reimbursement recommendations prior to public funding. This analysis aims to understand how the pCODR review process manages drugs approved through the NOC/c pathway.

Methods: pCODR recommendations available before mid-June 2020 were evaluated to identify drug submissions reviewed under the NOC/C pathway. Recommendations were categorized as either "positive" or "negative" and compared using a chi-squared test.
Results: pCODR issued 156 recommendations for unique drug-indication combinations. $35(22.4 \%)$ of those files were reviewed under the NOC/c pathway. Files reviewed under this pathway were statistically less likely to receive a positive reimbursement recommendation compared to files reviewed under the traditional NOC pathway $(62.9 \%$ vs. $81.8 \% ; \quad \mathrm{p}=0.02)$. Clinical uncertainty was the primary rationale for negative recommendations, with resubmissions leveraging additional trial data often being recommended.

Conclusions: The NOC/C pathway was designed to enable access to drugs with promising clinical data, while establishing mechanisms for the early data to be verified following market authorization. However, this uncertainty is the rationale often cited in these drugs receiving negative reimbursement recommendations. Alternative reimbursement models may be needed to ensure temporary access for patients while additional data is reviewed by pCODR.

\section{Profiles of Opioid Consumption Associated with an Increased Risk of Acute Opioid-Related Healthcare Events}

Kurteva S, Abrahamowicz M, Gomes T, Tamblyn R

Department of Epidemiology and Biostatistics, McGill University, Montreal, Canada, Clinical and Health Informatics Research Group, McGill University, Montreal, Canada siyana.kurteva@mail.mcgill.ca

Background: Multiple policy and public health interventions have been implemented to stem the ongoing opioid

J Popul Ther Clin Pharmacol Vol 27(4):e19-e54; December 1, 2020.

This article is distributed under the terms of the Creative CommonsAttribution-Non Commercial 4.0 International License. (C) 2020 CAPT. 
epidemic. While better pain management has guided policies for opioid use, there is limited evidence regarding how prescription patterns are associated with an increased risk of avoidable adverse events.

Methods: A cohort of patients discharged from two hospitals within an academic health center in Quebec, Canada, who filled an opioid prescription 3 months post-discharge was assembled. Data from the provincial health insurance agency to measure opioid dispensations, medical services and death in the one year post-discharge was retrieved. Multivariable Marginal Structural Cox Proportional Hazards models were used to determine the association between time-varying opioid use, including dose, duration and opioid type, and the risk of opioid-related emergency department (ED) visits, re-admissions or death.

Results: The 1,551 patients in the cohort had a mean age of 69 years $(S D=10.3)$. Among those who filled at least one opioid prescription, $16 \%$ of patients experienced an opioid-related ED visit, re-admission or all-cause death. Cumulative opioid duration of $>90$ days was associated with an adjusted hazard ratio (aHR) of 2.56 (95\% Cl:1.25 - 5.27), compared to 1-30 days of use. Mean daily dose of $\geq 90$ morphine milligram equivalent(MME) was associated with an aHR of $3.24 \quad(95 \% \quad \mathrm{Cl}: 1.43-7.35)$ compared to $\leq 50 \mathrm{MME}$.

Conclusion: We found increases in the risk of opioid-related ED visits/rehospitalizations or death with higher doses and increasing opioid use duration. Policies that limit the prescribed duration and dose may attenuate the risk of avoidable morbidity.

\section{A retrospective view on plan sustainability in 2019 from a large Canadian private payer}

Arora A, Nguyen S, Hayes J, Doobay J

Sun Life

anjila.arora@sunlife.com

Background: In 2019, drug spend continues to increase at an unsustainable rate compared to the rate of inflation. Highpriced drugs are beginning to create financial pressure points for which private health care plans must prepare. Private insurers and their industry actuarial pooling mechanisms were not designed to absorb the exorbitant cost increases that are currently being observed. Plan sponsors will face significant financial pressure if steps are not taken to proactively mitigate the risks to plan sustainability by this new generation of high-priced drugs.

Objective: To determine if the strategies implemented to reduce drug spend, such as product listing agreements, are helping to bend the benefits cost curve for plan sponsors and highlight how the strategies in place in 2019 have helped reduce drug spend.

Method: Using Sun Life's claims database, determine Sun Life's spend against inflation.

Results: Based on the rate of inflation, the expected drug spend increase from 2018 to 2019 should have been 1.9\%. However, the actual Sun Life drug spend in 2019 outpaced inflation and increased by $7.9 \%$. The latter includes approximately $\$ 80$ Million in savings generated through product listing agreements.

Conclusion: While spectacular movement has been made to improve plan sustainability, drug spend continues

J Popul Ther Clin Pharmacol Vol 27(4):e19-e54; December 1, 2020.

This article is distributed under the terms of the Creative CommonsAttribution-Non Commercial 4.0 International License. (C) 2020 CAPT. 
to rise above inflation at an alarming rate. Further work and collaboration by private payers, public payers and the pharmaceutical industry is needed to bend the benefits cost curve.

\section{The COVID-19 risk assessment model: an interactive epidemiologic modelling platform \\ Kirwin $\mathbf{E}^{1}$, Rafferty $\mathrm{E}^{1}$, Round $\mathrm{J}^{1,2}$, McCabe $\mathrm{C}^{1,3}$ \\ ${ }^{1}$ Institute of Health Economics, ${ }^{2}$ School of Public Health, University of Alberta, ${ }^{3}$ Department of Emergency Medicine, University of Alberta \\ jround@ihe.ca}

Background: Public health decision makers are challenged with formulating robust responses to the current COVID19 pandemic. Decision makers must determine when to introduce and relax interventions, which groups to target, and how to allocate scarce resources across multiple demands and patient groups. Current modelling efforts extrapolate trends from other jurisdictions and/or estimate the impact of a limited range and combination of interventions. There is a lack of widely available modelling resources which interactively predict outcomes under combinations of public health interventions (contact tracing, quarantine, social distancing) and prevention and treatment options (immunization, antiviral treatment). We have a developed a platform to enable end users in multiple settings (public health decision makers, state/provincial governments, federal governments) to evaluate a complete range of interventions on a common platform and therefore promote coherent, effective COVID-19 responses within and across jurisdictions. We have used data from Alberta, Canada, to for model development, but the platform is easily adaptable to any jurisdictional context. Our objective is to provide a modelling platform which is: (i) is broadly applicable and accessible, (ii) evaluates current and potential future interventions, and (iii) is structured to use high quality surveillance inputs, and account for uncertainty in model parameters.

Methods: The COVID-19 Risk Assessment Model (CRAM) is the basis of our platform. The full platform includes model fitting, evidence synthesis, expert elicitation, probabilistic, and interactive modelling components. The CRAM is an ordinary differential equation model which includes two risk, and 16 age groups, and disaggregates social distancing interventions into work, school, home, and other locations. The CRAM was developed for the province of Alberta, Canada, and we derive inputs from Alberta Health data holdings wherever possible, but the model is easily adaptable to other jurisdictions. The CRAM is designed to evaluate quarantine, test and trace, and social distancing interventions, as well as potential future immunization and antiviral treatment options. Health economic outcomes (cost, disutility) are included in model outputs to estimate Net Monetary Benefit (NMB) from both payer and societal perspectives. We calibrate our model to observed data using a latin hypercube generated with plausible parameter values for simultaneous calibration of unknown parameters. We estimate uncertainty distributions (comparing the fit of beta, uniform, and gamma distributions) for each of the calibrated parameters from

J Popul Ther Clin Pharmacol Vol 27(4):e19-e54; December 1, 2020.

This article is distributed under the terms of the Creative CommonsAttribution-Non Commercial 4.0 International License. 
the top $10 \%$ parameter sets in the hypercube, defined as those minimizing the sum of the normalized difference in observed outcomes and model estimates.

Model inputs leverage jurisdictional data as inputs. For inputs which cannot be estimated with jurisdictional data, such as the duration of the infectious and latency periods and economic inputs, we will draw from the literature and a national review produced by the Public Health Agency of Canada (PHAC). The fitted model samples from the distribution for each input over 10,000 simulations, and uncertainty in model outputs is represented as quantile-based credibility intervals.

Results: Our platform makes a

significant contribution to the existing resources because: (i) the model is structured to easily incorporate jurisdictional parameters and emerging evidence, (ii) the model will be made freely available in an open-source interactive format with a simple user interface, (iii) the model is structured to allow any combination of intervention implementation and timing to be compared, and (iv) the model provides health economic outcome predictions. Anticipated impacts of the final model platform are: (i) improved decision making and outcomes for end user jurisdictions, (ii) a consistent platform for decisions, improving coherence in policies implemented at all levels of decision making and across jurisdictions.

Conclusions: One of the greatest challenges of the COVID-19 pandemic has been balancing the health and safety of individuals, the capacity of the health system, and other social and economic needs of the population. By providing a platform to synthesize epidemiologic and economic outcomes in an NMB framework, better decisions will be made. The reasons for this are twofold: (i) jurisdictions will be enabled to evaluate tradeoffs between public health and broader economic concerns, and (ii) across jurisdictions and decision-making levels, decision makers can access a single platform, providing consistency and coherence in decision outcomes.

\section{Case study to explore patient- level impact of adoption of subsequent entry biologic anti- TNF medicines \\ Humphries $\mathrm{B}^{1,2}$, Adebayo $\mathrm{W}^{1}$, \\ Lamb-Palmer $\mathbf{D}^{\mathbf{1}}$, Henricks $\mathrm{P}^{1}$ \\ ${ }^{1} \mathrm{PDCl}$ Market Access, Ottawa, ON, \\ ${ }^{2}$ Department of Health Research \\ Methods, Evidence and Impact, \\ Hamilton, ON \\ brittany.humphries@pdci.ca}

Background: Canada has the second highest per capita biologic spending among OECD countries. Subsequent entry biologic (SEB) adoption remains low compared to other countries. The Canadian biosimilar industry, Health Technology Assessment Agencies, and payers have worked to enhance biosimilar adoption.

The objective of this analysis was to explore the patient-level impact of recent adoption efforts on SEB initiation of antiTNF medicines in the Canadian Private market.

Methods: This analysis was conducted using PDCl's Private Claims Database, representing an average annual sample of 1.6 million covered lives. The population of interest was patients with at least one claim for etanercept or infliximab between 2012 and March 31, 2020. Descriptive statistics (mean, 
standard-deviation [SD]) were used to describe trends in biologic and SEB initiation and switching. Subgroup analyses were conducted according to age, province, and gender.

Results: A total of 2,953 patients were identified for this analysis. 164 received a biosimilar, $48 \% \quad(n=79)$ of initiations were in the most recent 12-months (Apr 1, 2019 - March 31, 2020). 30 (18\%) biosimilar recipients were switched from the innovator with $26(87 \%)$ in the most recent six-months. The mean patient age when initiated with etanercept was $47.8 \quad(\mathrm{SD}=13.9) \quad$ years; $44.7 \%$ were male. The mean patient age when initiated with infliximab was 38.5 $(\mathrm{SD}=14.3)$ years; $51.5 \%$ were male. Conclusions: While this analysis found recent increases in switching from the innovator to biosimilars in the private market, early uptake of biosimilars was limited to new patient starts. Further research is necessary to explore the impact of switching on patients.

\section{Variability in prescription medication coverage for children and youth across Canada: A scoping review}

Ahmad $\mathbf{A}^{\mathbf{1}}$, Miregwa $\mathrm{B}^{2}$, Abbas $\mathrm{M}^{3}$, Holbrook $A^{4}$

${ }^{1}$ Bachelor of Health Sciences Program, McMaster University, Hamilton, Canada, ${ }^{2}$ Health Policy Graduate Program, McMaster University, Hamilton, Canada, ${ }^{3}$ Bachelor of Arts \&amp; Science Program, McMaster University, Hamilton, Canada, ${ }^{4}$ Division of Clinical Pharmacology \&amp; Toxicology, McMaster University, Hamilton, Canada ahmada32@mcmaster.ca

Background: Drug coverage in Canada is provided by at least 14 public drug plans and thousands of private insurance plans. Previous literature suggests that coverage varies, but typically focuses on the elderly, those with selected diseases, and those on social assistance.

Objective: To undertake a scoping review of recent literature to evaluate the variation in drug coverage for children and youth across Canada.

Methods: Bibliographic databases (i.e. Embase, CINAHL, Web of Science, Medline) and gray literature sources were screened. Papers published between January 2005 and December 2019 focusing on drug coverage for Canadians under 25 were identified. Results: 6 original reports met our criteria. There was minimal information about private plan coverage. 12 of 14 jurisdictions report coverage for individuals under 25 through some form of demographic-based or income-based public drug plan, while many residents of Northwest Territories and Nunavut receive coverage through the NonInsured Health Benefits program. Quebec provides coverage for the whole population with one public plan, while other jurisdictions have additional disease-based plans varying in age of eligibility and disease type. Children and youth covered by demographic or income criteria have access to jurisdictional formularies. Three of the 14 public plans report no cost sharing for individuals under 25 that meet specific criteria, while the other 11 report cost sharing models.

Conclusion: For children and youth in Canada, information on private plan drug coverage is lacking, but there is evidence of variability across the 14 public drug plans in terms of age of access and disease-specific criteria.

J Popul Ther Clin Pharmacol Vol 27(4):e19-e54; December 1, 2020.

This article is distributed under the terms of the Creative CommonsAttribution-Non Commercial 4.0 International License. 
28. Development of an adapted operationalized definition of nudging for healthcare and medication optimization

Lee $\mathbf{J}^{\mathbf{2}}$, Peters $\mathrm{R}^{2}$, Zhang $\mathrm{J}^{2}$, Holbrook

$A^{1}$, Dolovich $L^{3}$

${ }^{1}$ Department of Medicine, McMaster

University, ${ }^{2}$ Michael DeGroote School of

Medicine, McMaster University, ${ }^{3}$ Leslie

Dan Faculty of Pharmacy, University of

Toronto

justin.lee@medportal.ca

Background: Behavioural economics suggests that clinicians' and patients' medication choices are influenced by environmental factors and cognitive biases. Based on this theory, nudging has been proposed as a strategy to improve the safe and effective use of medications. However, there is no consensus definition for a "nudge". In preparation for a systematic review examining the effectiveness of nudging to improve prescribing, we sought to develop a precise definition of nudging for a healthcare context.

Methods: We conducted a literature review and consultations with content experts to map out core nudge components. These components formed the basis of a nudging definition developed for use in a healthcare or medication context. A decision tree was developed to evaluate features that can distinguish nudges from other behavioural interventions (e.g. shoves, boosts). We pilot tested the definition on a random sample of 100 studies to evaluate inter-rater agreement.

Results: We found variable nudging definitions depending on the context and field of study (e.g. economics, public health). Core features include interventions that influence behaviour through heuristic processing and are non-coercive, non-fiscal, and do not restrict freedom of choice. We found that prompt or reminder nudges have key features that need to be critically evaluated because they exist on a continuum that can make interventions more and less nudge-like. These include the medium, content, interactivity and frequency of the delivered intervention. The mean weighted kappa of pilot testing was 0.82 .

Conclusion: We developed a nudging definition for use within a healthcare context with good inter-rater reliability.

29. Pre-existing autoimmune disease and immune-related adverse events (irAE) with checkpoint inhibitors in melanoma

Machado MAA ${ }^{1}$, Moura $\mathrm{CS}^{2}$, Chan $\mathrm{K}^{3}$, Curtis $\mathrm{JR}^{4}$, Hudson $\mathrm{M}^{5}$, Abrahamowicz $M^{6}$, Colmegna $I^{1}$, Jamal $R^{7}$, Pilote $L^{1}$, Chan $\mathrm{AW}^{3}$, Bernatsky $\mathrm{S}^{1}$

${ }^{1}$ McGill University, Department of Medicine, Canada, ${ }^{2}$ Research Institute of the McGill University Health Centre, Centre for Outcomes Research and Evaluation, Canada, ${ }^{3}$ University of Toronto, Department of Medicine, Canada, ${ }^{4}$ University of Alabama at Birmingham, Department of Medicine, USA, ${ }^{5}$ Lady David Research Institute for Medical Research, Canada, ${ }^{6}$ McGill University, Department of Epidemiology, Biostatistics and Occupational Health, Canada, ${ }^{7}$ Centre Hospitalier de I'Universite de Montreal, Canada marina.machado@mail.mcgill.ca

Background: Melanoma patients with pre-existing autoimmune disease may be at higher risk of developing $A E$ associated with checkpoint inhibitors. We aimed to evaluate $A E$ in melanoma

J Popul Ther Clin Pharmacol Vol 27(4):e19-e54; December 1, 2020.

This article is distributed under the terms of the Creative CommonsAttribution-Non Commercial 4.0 International License. (C) 2020 CAPT. 
patients using checkpoint inhibitors with and without pre-existing autoimmune diseases.

Methods: We selected adults with metastatic melanoma that initiated therapy with ipilimumab (IPI), pembrolizumab (PEM), nivolumab (NIV), or NIV/IPI over Jan 2012-July 2017 using MarketScan Databases. We identified autoimmune disease based on diagnostic codes from physician visits/hospitalizations: preexisting autoimmune disease was defined in 12 months before initiation of therapy (time-zero) and incident AE (outcome) was defined from time-zero until the earliest date of in-hospital death, loss of health/drug plan, end of study period (Dec 2017), gap between doses $\geq 60$ days, or therapy switch. We estimated AEs rates and hazard ratios (HR) with 95\% confidence intervals $(\mathrm{Cl})$ adjusted for age, sex, calendar year, comorbidities, past health care use, past and current cancer therapy, and pre-existing autoimmune disease.

Results: We studied 2315 patients initiating checkpoint inhibitors. The median age was 60 years, $62.1 \%$ were male, and $27.7 \%$ had pre-existing autoimmune disease. The rate (per 100 person-years) of AEs in patients with pre-existing autoimmune diseases was $7.3(95 \% \mathrm{Cl}$ 4.2-12.6) versus $4.1(95 \% \mathrm{Cl} 2.5-6.6)$ in those without autoimmune disease. Presence of pre-existing autoimmunity was associated with

higher $\mathrm{AE}$ risk (adjusted $\mathrm{HR} 2.17,95 \% \mathrm{Cl}$ 1.01-4.66); AE risk was lower with IPI vs. NIV/IPI (adjusted HR 0.19 95\% Cl 0.04$0.86)$.

Conclusions: We observed a trend of higher AE risk associated with checkpoint inhibitors in metastatic melanoma patients with pre-existing autoimmunity.
30. Characteristics of a population exposed to a disease-modifying drug for multiple sclerosis in the realworld setting (1996-2017)

Ng HS ${ }^{1}$, Zhu $F^{1}$, Kingwell $E^{1}$, Zhao $Y^{1}$, Evans $\mathrm{C}^{2}$, Svenson $\mathrm{L}^{3}$, Fisk JD ${ }^{4}$, Marrie $\mathrm{RA}^{5}$, Tremlett $\mathrm{H}^{1}$

${ }^{1}$ Department of Medicine, Division of Neurology and the Djavad Mowafaghian Centre for Brain Health, University of British Columbia, Vancouver, BC, Canada, ${ }^{2}$ College of Pharmacy and Nutrition, University of Saskatchewan, Saskatoon, SK, Canada, ${ }^{3}$ Department of Community Health Sciences, Cumming School of Medicine, University of Calgary, Calgary, AB, Canada, Alberta Ministry of Health, Edmonton, AB, Canada, Division of Preventive Medicine \&amp; School of Public Health, University of Alberta, Edmonton, AB, Canada, ${ }^{4}$ Nova Scotia Health Authority and the Departments of Psychiatry and Medicine, Dalhousie University, Halifax, NS, Canada, ${ }^{5}$ Departments of Internal Medicine and Community Health Science, Max Rady College of Medicine, Rady Faculty of Health Sciences, University of Manitoba, Winnipeg, MB, Canada, huahshin.ng@ubc.ca

Background: Relatively little is known about the use of disease-modifying drugs (DMDs) for multiple sclerosis (MS) in the population-based universal healthcare setting. We described the characteristics of a population with MS who were exposed to their first DMD in the realworld setting.

Methods: Using linked population-based health administrative data, we identified all adults (aged $\geq 18$ years) with MS in the province of British Columbia, Canada between 1996 and

J Popul Ther Clin Pharmacol Vol 27(4):e19-e54; December 1, 2020.

This article is distributed under the terms of the Creative CommonsAttribution-Non Commercial 4.0 International License. (C) 2020 CAPT. 
2017. Individuals were followed from their first recorded demyelinating event to the earliest of death, emigration, or study end (December/2017).

Results: Overall, 4283 with MS filled a DMD prescription during the study period. Most were women $(n=3132$, $73 \%)$ and $17 \% \quad(n=741)$ had some comorbidity (Charlson Comorbidity Index 21). The mean (SD) age at first DMD ranged from $37.2(10.0)$ years for alemtuzumab to $43.0(10.6)$ years for teriflunomide. Nearly $20 \%(n=724)$ were $\geq 50$ years of age when they filled their first DMD prescription. From 1996-2012, the most common first DMD prescriptions filled were for either betainterferon $(n=2548 / 3190,80 \%)$ or glatiramer acetate $(n=612 / 3190,19 \%)$. From 2013-2017, the most common first DMD prescriptions filled were for glatiramer acetate $(n=379 / 1093,35 \%)$, dimethyl fumarate $(n=282 / 1093,26 \%)$ or teriflunomide $\quad(n=182 / 1093,17 \%)$.

Conclusions: Almost 1 in 5 persons with MS had at least some comorbidity and nearly 1 in 5 were $\geq 50$ years old at the time of their first DMD. As these individuals are often excluded from clinical trials, our data illustrates the need to understand the harms and benefits of DMD use in these understudied groups.

\section{Is treatment with sacubitril- valsartan compared to ACE inhibitors or ARBs more beneficial for women with heart failure?}

Sohani Z, Behlouli H, Soares de Moura C, Abrahamowicz M, Pilote L McGill University Health Centre, 1001 Boulevard Decarie, Montreal, QC H4A 3J1

zahra.sohani@mail.mcgill.ca
Background: Guidelines for heart failure (HF) management are based on RCTs among men with reduced ejection fraction. Recently, PARAGON-HF suggested a benefit of sacubitrilvalsartan among women with preserved ejection fraction.

Objective: We studied whether efficacy of treatment with sacubitril-valsartan compared to ACE inhibitors or ARBs varied by sex among patients with HF. Methods: Data was derived from Truven MarketScan Databases between January 1, 2011 and Dec 31, 2017. We included patients with a diagnosis of HF on treatment with ACE inhibitors, ARBs, or sacubitril-valsartan based on the first prescription after diagnosis. 61,585 patients treated with an ACE inhibitor, 42,746 patients using ARBs, and 8,338 patients using sacubitril-valsartan were included. The primary outcome was a composite of re-admissions for HF and death from cardiovascular causes. We also studied secondary efficacy and safety outcomes.

Results: The incidence of the composite outcome was $27.66 \%$ in the ACE inhibitors/ARB group and $11.43 \%$ in the sacubitril-valsartan group (adjusted HR $0.77,95 \% \mathrm{Cl} 0.71-0.84)$. A protective effect of sacubitril-valsartan was evident for both sexes (adjusted HRwomen 0.88, $95 \% \mathrm{Cl} 0.78$ - 0.99; adjusted HRmen $0.78,95 \% \mathrm{Cl} 0.71-0.86)$. Patients using sacubitril-valsartan experienced lower rates of combined hypotension, renal dysfunction, hyperkalemia, and angioedema. Secondary outcomes and adverse events did not vary by sex.

Conclusion: Similar to PARAGON-HF, we observe reduced hospitalizations and cardiovascular death from treatment with

J Popul Ther Clin Pharmacol Vol 27(4):e19-e54; December 1, 2020.

This article is distributed under the terms of the Creative CommonsAttribution-Non Commercial 4.0 International License. (C) 2020 CAPT. 
sacubitril-valsartan among women. However, we also report a therapeutic benefit in men. This is the first report of overall efficacy of sacubitril-valsartan evident for both sexes.

Keywords: heart failure, sacubitrilvalsartan, sex effect, reduced ejection fraction, preserved ejection fraction

\section{Persistence in rheumatoid arthritis patients on biosimilar and bio-originator etanercept: A pooled analysis of pan-Canadian cohorts} Moura CS ${ }^{1}$, Choquette $D^{2}$, Coupal $L^{2}$, Schieir $\mathrm{O}^{3}$, Bykerk VP ${ }^{4,5}$, Valois $\mathrm{MF}^{1}$, Boire $\mathrm{G}^{6}$, Maksymowych WP ${ }^{7}$, Bernatsky $S^{1}$, ${ }^{1}$ McGill University, Canada, ${ }^{2}$ Institut de Rhumatologie de Montreal, Canada, ${ }^{3}$ University of Toronto, Canada, ${ }^{4}$ Mount Sinai Hospital, Canada, ${ }^{5}$ Hospital for Special Surgery, USA, ${ }^{6}$ University of Sherbrooke, Canada, ${ }^{7}$ University of Alberta, Canada cristiano.soaresdemoura@mail.mcgill.ca

Data descriptions of drug persistence (and comparisons with the originator product, ETA-O) are still scarce.

Objective: To describe and compare persistence of ETA-B and ETA-O in RA. Methods: We used data from four ongoing, prospective cohorts in Canada: the Canadian Early Arthritis Cohort (CATCH), the Rheumatoid Arthritis Pharmacovigilance Program and Outcomes Research in Therapeutics (RAPPORT), the Early Undifferentiated Polyarthritis (EUPA) cohort, and the RHUMADATA registry. We studied biologic-naive and biologic-experienced RA adults initiating ETA-B or ETA-O between Jan. 2015 and Oct. 2019. We assessed persistence of therapy in the first 12 or 24 months, measured as time from therapy initiation to discontinuation. Multivariable Cox regression models were performed with each cohort dataset separately. Model variables included age, sex, comorbidity, past biologic use, and disease duration. Cohort-estimated hazard ratios (HR) were pooled using randomeffects meta-analysis.

Results: We identified 262 episodes of etanercept use (118 ETA-B and 144 ETA-O) from 250 RA patients. Across cohorts, there was considerable variation in RA duration. In the pooled analysis, the HR for discontinuation at 24 months comparing ETA-B to ETA-O was 0.51 (95\% confidence interval, $\mathrm{Cl}$ : 0.26 $0.98)$. The pooled analysis for therapy discontinuation at 12 months adjusted HR in this analysis was $0.82(95 \% \mathrm{Cl}: 0.42-$ $1.60)$.

Conclusions: Despite wide confidence intervals, the 24-month data suggested potential better persistence with ETA-B versus $\mathrm{ETA}-\mathrm{O}$, with a similar trend at 12 months. Some of the observed associations may be related to residual confounding.

33. Personalized comparisons of flare rates after hydroxychloroquine tapering or discontinuation in systemic lupus

Almeida-Brasil $\mathbf{C C}^{1}$, Pineau $\mathrm{CA}^{2}$, Vinet $\mathrm{E}^{1,2}$, Hanly JG ${ }^{3}$, Peschken $\mathrm{CA}^{4}$, Clarke $\mathrm{AE}^{5}$, Fortin $\mathrm{PR}^{6}$, Abrahamowicz $\mathrm{M}^{1,7}$, Bernatsky $\mathrm{S}^{1,2}$

${ }^{1}$ Research Institute of the McGill University Health Centre, ${ }^{2}$ McGill University Health Centre, ${ }^{3}$ Queen Elizabeth II Health Sciences Centre and Dalhousie University, ${ }^{4}$ University of Manitoba, ${ }^{5}$ University of

Calgary, ${ }^{6} \mathrm{CHU}$ de Quebec - Universite Laval, ${ }^{7}$ McGill University celline.brasil@mail.mcgill.ca 
Background: Given unclear risk/benefits in hydroxychloroquine (HCQ) long-term use, Systemic Lupus (SLE) patients and physicians struggle with decisions about tapering/stopping HCQ. We aimed to identify factors associated with SLE flare risk after $\mathrm{HCQ}$ is tapered or discontinued, and to compare flare rates among high-risk subgroups.

Methods: We analyzed prospective data from 5 Canadian cohorts of SLE patients using HCQ followed between 1999-2019. We assessed patients from date of $\mathrm{HCQ}$ tapering or discontinuation until disease flare. Multivariable Cox regression was used to identify demographic and baseline clinical factors associated with time-to-first flare. We compared unadjusted flare rates and $95 \%$ Cls stratified by the risk factors. A third cohort of patients remaining on HCQ was used for comparison.

Results: After tapering HCQ $(\mathrm{N}=398)$, flare risk was greater for nonCaucasians, patients with active SLE and those on prednisone. Patients with $>1$ of these characteristics at the time of HCQ taper had a higher flare rate (4.2/ 1000 person-years, $95 \% \mathrm{Cl} 3.6-4.9)$ than patients without any such characteristics (2.8, 95\% Cl 2.3-3.4). After discontinuing $\mathrm{HCQ}(\mathrm{N}=395)$, flare risk was greater for non-Caucasians and those younger $(<25$ years) at SLE onset. Patients belonging to one or both of these subgroups had an increased flare rate after HCQ discontinuation $\quad(4.2, \quad 95 \% \mathrm{Cl} \quad 3.5-5.0)$ versus those without these factors (2.2, $95 \% \mathrm{Cl} 1.8-2.6)$. There was no significant difference in flare rates between patients remaining on $\mathrm{HCQ} \quad(\mathrm{N}=621)$ with or without risk factors.
Conclusions: Being aware of these factors may help physicians and patients in personalizing decisions regarding $\mathrm{HCQ}$ de-escalation or maintenance.

\section{Using real world data to determine health system costs of Canadians diagnosed with chronic lymphocytic leukemia}

Seung $\mathbf{S J}^{1}$, Hurry $\mathrm{M}^{2}$, Hassan $\mathrm{S}^{1}$, Walton $\mathrm{RN}^{2}$, Elnoursi $\mathrm{A}^{2}$, Scheider $\mathrm{KAB}^{2}$, Edwin $\mathrm{JJ}^{2}$, Aw ATW ${ }^{3}$ ${ }^{1}$ HOPE Research Centre, Sunnybrook Research Institute, Toronto, ON, Canada, ${ }^{2}$ AstraZeneca Canada, Mississauga, ON, Canada, ${ }^{3}$ The Ottawa Hospital General Campus, Ottawa, ON, Canada soojin.seung@sunnybrook.ca

Objectives: Understanding the real world economic impact of CLL is critical. The objective of this study was to determine the health system costs of CLL patients treated in Ontario, Canada.

Methods: Patients diagnosed and treated between January 1, 2010 and December 31, 2017 were identified in the Ontario Cancer Registry and linked to provincial administrative databases, capturing hospitalizations, cancer clinic visits, physician services and novel treatments (radiation and inexpensive chemotherapies were excluded). Total cohort, annual and mean per patient/control costs (CAD 2017) were determined using a costing methodology available at ICES called GETCOST. Short-term episodes (e.g., hospitalizations) attributed costs by multiplying the encounter's resource intensity weight by an annual cost per weighted case; long-term episodes (e.g., complex care) attributed costs by weighted days, and costs of visit-based 
encounters were determined by utilization.

Results: 2,572 CLL patients/cases were identified and matched with 7,611 controls (median age 68 years; 66\% male). The overall total cost for cases was $\$ 254.7 \mathrm{M}$ (mean cost per patient= $\$ 99,900$ ); oral medications based on list price $(\$ 56.5 \mathrm{M})$, inpatient hospitalizations $(\$ 49.1 \mathrm{M})$, and cancer clinic visits $(\$ 46.2 \mathrm{M})$ were the top three cost contributors. The mean cost per control= $\$ 46,382$ with inpatient hospitalizations, physician services and oral medications the top three cost contributors. For CLL patients, year 1 after diagnosis had the highest mean cost $(\$ 31,928)$ followed by year $2(\$ 17,665)$.

Conclusions: Real world costs for CLL patients may have been increasing over time. Exploring whether investment in new novel agents resulted in improved survival would be key.

35. Retrospective cohort study of real-world treatment patterns and overall survival in patients with chronic lymphocytic leukemia (CLL) diagnosed between 2010-2017 in Ontario, Canada

Hassan $\mathbf{S}^{1}$, Seung $\mathrm{SJ}^{1}$, Hurry $\mathrm{M}^{2}$, Walton $\mathrm{RN}^{2}$, Elnoursi $\mathrm{A}^{2}$, Scheider $\mathrm{KAB}^{2}$, Edwin $\mathrm{JJ}^{2}$, Aw ATW ${ }^{3}$ ${ }^{1}$ HOPE Research Centre, Sunnybrook Research Institute, Toronto, ON, Canada, ${ }^{2}$ AstraZeneca Canada, Mississauga, ON, Canada, ${ }^{3}$ The Ottawa Hospital General Campus, Ottawa, ON, Canada
Objectives: With recent advances in treatment of CLL, it is important to understand emerging treatment patterns and associated outcomes. A population-based study was undertaken to describe the management and survival of CLL patients in Ontario, Canada.

Methods: Patients diagnosed with CLL between January 1, 2010 and December 31, 2017 were identified in the Ontario Cancer Registry and linked to provincial administrative databases. Treatment patterns by line of therapy were characterized, including analyses of time to initiation and between therapies. Overall survival was calculated.

Results: 2,887 CLL patients were identified (median age 68yr; 67\% male). The mean time from diagnosis to first line (1L) treatment was 651 days with $35 \%$ of patients receiving fludarabinecyclophosphamide-rituximab (FCR) based treatment, $71 \%$ of patients did not yet receive second line (2L) therapy and did not have subsequent follow up. Of the 827 patients on $2 \mathrm{~L}$ therapy, $65 \%$ received ibrutinib. After the introduction of publicly funded novel agents in 2015, a shift in treatment patterns away from FCR and chlorambucil based regimens was observed. Overall mean survival for the cohort from diagnosis was 6.8yrs, and mean 5 year probability of survival was $72.4 \%$.

Conclusions: A shift in treatment patterns for CLL can be seen with the introduction of newer therapies, such as ibrutinib. The results can support healthcare decisionmakers by characterizing the size of this patient population, real world treatment patterns and survival outcomes for patients with CLL.

J Popul Ther Clin Pharmacol Vol 27(4):e19-e54; December 1, 2020.

This article is distributed under the terms of the Creative CommonsAttribution-Non Commercial 4.0 International License. (C) 2020 CAPT. 
36. Prevalence and characteristics of progressive fibrosing interstitial lung diseases

Farooqi M, Wongkarnjana A, Sakkat A, Chong SG, Alobaid F, Scallan C, Hambly N, Cox G, Kolb M Department of Medicine, Division of Respirology, McMaster University malik.farooqi@medportal.ca

Background: Progressive fibrosing interstitial lung disease (PF-ILD) is characterized by increasing fibrosis and a clinical course similar to idiopathic pulmonary fibrosis (IPF). Antifibrotic therapy reduces disease progression in PF-ILD, irrespective of underlying diagnosis. The prevalence and characteristics of PF-ILD have not been well described outside of clinical trials. Methods: Participants of the Canadian Registry for Pulmonary Fibrosis (CAREPF), McMaster University site, were studied (Nov 2015 to March 2020). NonIPF patients with fibrosis on HRCT were classified as PF-ILD if they showed, over the preceding 24 months: relative FVC decline $10 \%$, or any 2 of: relative FVC decline $5-10 \%$, worsening respiratory symptoms or worsening fibrosis on HRCT (based on chart and image review).

Results: 234 patients without IPF had fibrosing ILD (mean 65 \pm 12 years, 42\% male). 101 (43\%) met criteria for PF-ILD. PF-ILD and controls did not differ by age, sex, ethnicity, or underlying diagnosis. PF-ILD were more likely to have a smoking history, had a trend towards lower baseline FVC $(2.50 \pm 0.86$ vs $2.72 \pm 0.96 \mathrm{~L}, \mathrm{p}=0.08$ ) and had lower baseline DLCO $(12.09 \pm 4.03$ vs $14.78 \pm 6.39 \mathrm{ml} / \mathrm{min} / \mathrm{mmHg}, \quad \mathrm{p}=0.006)$.
PF-ILD were most commonly due to rheumatoid arthritis (18\%), chronic hypersensitivity pneumonitis (14\%), unclassifiable ILD (10\%), and scleroderma $(8 \%)$. Mean annual FVC decline was $173 \pm 250 \mathrm{ml}$. In a catchment area of 1.4 million, we estimate the prevalence of PFILD is 7.2 per 100,000 people.

Conclusions: PF-ILD is an important phenotype of patients with ILD. Significant decline in FVC is evident in this real-world cohort, to a degree similar to IPF. These findings highlight the role of anti-fibrotic therapy in PF-ILD.

\section{Influence of drug safety advisories on drug utilization: an international interrupted time series and meta- analysis study \\ Morrow RL ${ }^{1}$, Mintzes BJ ${ }^{2}$ \\ 1Department of Anesthesiology, Pharmacology \&amp; Therapeutics, University of British Columbia, Canada, ${ }^{2}$ School of Pharmacy, University of Sydney, Australia rlmorrow@mail.ubc.ca}

Background: Regulatory drug safety advisories represent a key strategy for managing risk from drug harms. We evaluated the impact of drug advisories on drug utilization in Canada, the US, the UK and Denmark.

Method: We selected 25 drug safety advisories issued in one or more of the four countries during 2009-2015. We included advisories for frequently used drugs and excluded advisories for vaccines, drug-drug interactions or overthe-counter drugs. We analyzed data from 24 months before to 11 months after the month of each advisory. Monthly drug utilization outcomes were

J Popul Ther Clin Pharmacol Vol 27(4):e19-e54; December 1, 2020.

This article is distributed under the terms of the Creative CommonsAttribution-Non Commercial 4.0 International License. (C) 2020 CAPT. 
numbers of prescriptions, or defined daily doses for dose-related advisories, per 100,000 population. We used interrupted time series models to estimate the percentage difference in actual versus predicted post-advisory drug utilization, in the first of the four countries to issue an advisory on a given drug harm. We used random effects meta-analysis to estimate the average effect across all advisories.

Results: Among all drug safety advisories, the average effect on drug utilization was a decline of $5.0 \%(95 \%$ $\mathrm{Cl}, 0.8 \%$ to $9.3 \%$ ), relative to predicted levels. The largest change was a $29 \%$ $(95 \% \mathrm{Cl}, 27 \%$ to $30 \%)$ reduction in pioglitazone use following a bladder cancer advisory. Few drug advisories (5/ 25) were followed by a decline in drug use of greater than $10 \%$.

Conclusion: The average effect of regulatory drug safety advisories on prescribing was small. If the goal of regulatory drug safety advisories is to influence prescribing to minimize drug harms, current risk communication strategies will likely need to be enhanced.

\section{A review of 20 years of drug delisting: what are the learnings for Canadian policy-makers? \\ Maier-Downing T, Liu J Amaris Consulting Inc. teagan.maierdowning@amaris.com}

Background: Canadian pharmaceutical health policy has been undergoing significant review. Amongst important initiatives, stakeholders are considering drug delisting as a management strategy to control drug spending. A recent initiative proposes real world data (RWD) collection to re-evaluate drugs for continued reimbursement (i.e. CanREValue). This review article assessed the impact of past drug delisting decisions in Canada, as well as in European countries. We analyzed opportunities and pitfalls for Canadian pharmaceutical health policy decisionmakers.

Methods: A targeted literature review (TLR) was conducted in relevant databases (EMBASE, Medline, Cochrane, PubMED, PAIS Index, and CINAHL) to identify articles evaluating public formulary management in Canada and Europe within the last 20 years.

Results: A total of 414 abstracts were identified. A total of 13 articles met the inclusion criteria and were extracted for: countries involved, drug delisting details (e.g., reasons), quantitative evidence of impact (i.e. drug plan expenditure and prescribing/ dispensing pattern change), and qualitative evidence of impact (i.e. physician/patient opinions). Four articles demonstrated that there was a decrease in drug plan expenditure following delisting, however savings appeared relatively modest. Two articles suggested that education programs should be enforced for physicians and patients to achieve optimal patient response.

Conclusion: This review demonstrated that drug delisting has been a relatively rare and complex process. Savings have therefore been modest, especially considering the intense policy investment required. Success factors to consider before engaging in a delist are discussed as well as some alternatives to delisting.

J Popul Ther Clin Pharmacol Vol 27(4):e19-e54; December 1, 2020.

This article is distributed under the terms of the Creative CommonsAttribution-Non Commercial 4.0 International License. (C) 2020 CAPT. 
39. Report on the incompatibility of the proposed PMPRB guidelines with the perspective of patients/caregivers and the future of new launches of drugs for rare disease (DRDs) in Canada Lech $\mathbf{R}^{1}$, Chattha $\mathrm{R}^{1}$, Jeffery $\mathrm{W}^{1}$, Chow $\mathrm{G}^{1}$, Mann $\mathrm{K}^{1}$, Malmberg $\mathrm{C}^{1}$, Barber $\mathrm{G}^{1^{*}}$, Forte $\mathrm{M}^{1^{*}}$, Forte $\mathrm{L}^{1}$

${ }^{1}$ Patient Access Solutions Inc., 219 Dufferin St., Suite 210B, Toronto, ON M6K 3J1

${ }^{*}$ Full-time student

Conflict of Interest: Patient Access Solutions prepares submissions to the PMPRB and HTA organizations for some DRD manufacturers

Source of Funding: Funded in part by RAREi (The Canadian Forum for Rare Disease Innovators)

Background: Patented Medicine Prices Review Board's (PMPRB's) proposed Canadian pricing guidelines were informed by the "Insight into the spending on expensive drugs for rare diseases" report. A review of the report and the draft guidelines was undertaken to determine if PMPRB's concern over DRD pricing is warranted.

Methods: Four key analyses were performed: 1) findings of the report were critically appraised to determine if the conclusions are evidence based; 2) the guidelines were assessed to evaluate whether DRD pricing would be unduly disadvantaged; 3) a revised analysis of the historical DRD public expenditure was prepared to contrast with the PMPRB analysis; 4) projected DRD costs were compared with select national expenditures to provide perspective.
Results: An alternate conclusion was readily found for all of PMPRB's key findings based on the data presented. The guidelines were found to unfairly disadvantage DRDs in the application of pharmacoeconomic (PV) and therapeutic (TV) value tests. Re-analysis of costs excluding oncology medications due to their expanded uses showed that Canadian DRD expenditure was below international norms and represented only $2.5 \%$ (versus $9.4 \%$ ) of the total 2019 pharmaceutical spend. Annual public DRD expenditure (\$0.3B) represented less than $0.2 \%$ of the total public healthcare budget.

Conclusions: The critical appraisal and re-analysis shows that scrutiny over the cost of DRDs in Canada is unfounded. The proposed PMPRB guidelines unfairly disadvantage DRDs and will discourage, if not eliminate, the availability of these life changing treatments for Canadians in need.

\section{Impact of policy changes on utilization of community medication review services in Ontario among people living with diabetes \\ Shakeri $\mathbf{A}^{\mathbf{1}}$, Gamble $\mathrm{JM}^{2}$, MacCallum \\ $\mathrm{L}^{1}$, Dolovich $\mathrm{L}^{1}$, Cadarette $\mathrm{SM}^{1,3}$ \\ ${ }^{1}$ Leslie Dan Faculty of Pharmacy, University of Toronto, Toronto, Canada, ${ }^{2}$ School of Pharmacy, University of Waterloo, Kitchener, Canada, ${ }^{3}$ ICES, Toronto, Canada ahmad.shakeri@mail.utoronto.ca}

Background: Since 2007, the Ontario government has funded pharmacy medication review services (MedsCheck Annual [MCA]) for residents taking 3 or

J Popul Ther Clin Pharmacol Vol 27(4):e19-e54; December 1, 2020.

This article is distributed under the terms of the Creative CommonsAttribution-Non Commercial 4.0 International License. (C) 2020 CAPT. 
more drugs for chronic conditions. In 2010, MedsCheck was broadened to include patients with diabetes (MCD). In 2016, a policy change added several required components to $\mathrm{MCD}$, including individualized goal-setting, and evidence of diabetes-specific education for pharmacists. The objective of our study was to examine the impact of the 2016 policy change on the use of MedsCheck among adults with diabetes.

Methods: We used a validated algorithm to identify adults (19+ years) with diabetes in Ontario 24-months pre-and post-intervention (October 2016) using healthcare administrative data. Segmented regression was used to identify the immediate change and 24month trend in the monthly rate of MedsCheck services per 10,000 adults with diabetes, after controlling for seasonality, non stationarity, and autocorrelation.

Results: Service delivery was stable in the two-years prior to intervention, with rate of $355 / 10,000$ for any MedsCheck service, 228/10,000 for MCD, and 122/ 10,000 for MCA in September 2016. An immediate decline in use was observed ( '61\% across any MedsCheck, ^’74\% MCD, ${ }^{\wedge} 37 \%$ MCA) in October 2016. Thereafter, use of MCA services increased, exceeding predicted values by September 2018 (+2\%). In contrast, minimal change was seen for MCD and rates remained lower than predicted by September 2018 ('64\% MCD).

Conclusions: $A$ decline in the rate of adults with diabetes receiving MedsCheck services was seen after the policy change, with evidence of some displacement from MCD to MCA.
41. Evaluation of the long-term costeffectiveness of the Dexcom G6 continuous glucose monitor versus self-monitoring of blood glucose in people with type 1 diabetes in Canada

Roze $\mathbf{S}^{1}$, Isitt $\mathrm{JJ}^{2}$, Smith-Palmer $\mathrm{J}^{3}$, Lynch $\mathrm{P}^{2}$

${ }^{1}$ Vyoo Agency, Paris, France, ${ }^{2}$ Vyoo

Agency, San Diego, CA, USA, ${ }^{3}$ Ossian

Health Economics and Communications,

Basel, Switzerland

sroze@vyoo-agency.com

Background and Objectives: The Dexcom G6 real time continuous glucose monitoring (RT-CGM) system is one of the most sophisticated RT-CGM systems developed to date and became available in Canada in 2019. RT-CGM is associated with improved glycemic control and reduced incidence of hypoglycemic events and reduced fear of hypoglycemia (FoH) relative to selfmonitoring of blood glucose (SMBG) but at higher cost. Therefore, a health economic analysis was performed to determine the long-term cost-effectiveness of the Dexcom G6 RT-CGM system versus SMBG in adults with type 1 diabetes (T1D) in Canada. Methods: The analysis was performed using the IQVIA Core Diabetes Model. Based on clinical trial data, RT-CGM, patients with a mean baseline $\mathrm{HbA} 1 \mathrm{c}$ of $8.6 \%$ (70 mmol/ mol) were assumed to have a $\mathrm{HbA1c}$ reduction of $1.0 \%(10 \mathrm{mmol} / \mathrm{mol})$ with $\mathrm{RT}$ CGM versus a $0.4 \%(4 \mathrm{mmol} / \mathrm{mol})$ reduction with SMBG. The Dexcom G6 RT-CGM system was also associated with a quality of life benefit of owing to reduced $\mathrm{FoH}$ and the elimination of fingerstick testing.

Results: The Dexcom G6 RT-CGM was projected to improve mean quality adjusted

J Popul Ther Clin Pharmacol Vol 27(4):e19-e54; December 1, 2020.

This article is distributed under the terms of the Creative CommonsAttribution-Non Commercial 4.0 International License. (C) 2020 CAPT. 
life expectancy by 2.09 quality-adjusted life years (QALYS) relative to SMBG (15.52 QALYs versus 13.43 QALYs) but mean total lifetime cots were CAD 35,353 higher with RT-CGM (CAD 227,357 versus CADÂ 192,004) resulting in an incremental costeffectiveness ratio (ICER) of CAD 16,931 per QALY gained. Sensitivity analyses revealed that assumptions relating to the quality of life benefit associated with reduced $\mathrm{FoH}$ and the elimination of fingerstick testing with RTCGM were the key drivers of costeffectiveness.

Conclusions: For adults with T1D based in Canada, RT-CGM is associated with improved glycemic control and quality of life benefits owing to a reduced $\mathrm{FoH}$ and elimination of the requirement for fingerstick testing and over a lifetime time horizon is costeffective relative to SMBG.

J Popul Ther Clin Pharmacol Vol 27(4):e19-e54; December 1, 2020.

This article is distributed under the terms of the Creative CommonsAttribution-Non Commercial 4.0 International License. (C) 2020 CAPT. 
Author Index:

\begin{tabular}{|l|l|}
\hline Author & $\begin{array}{l}\text { Abstract } \\
\text { Number }\end{array}$ \\
\hline Abbas M & 27 \\
\hline Abrahamowicz M & $23,29,31,33$ \\
\hline Adebayo W & 26 \\
\hline Ahmad A & 27 \\
\hline Almeida-Brasil CC & 33 \\
\hline Alobaid F & 36 \\
\hline Andrew MK & 1 \\
\hline Arora A & 24 \\
\hline Arthur E & 22 \\
\hline Aw ATW & 34,35 \\
\hline Aydin S & 13 \\
\hline Ball G & 22 \\
\hline Bally M & 19 \\
\hline Barber G & 39 \\
\hline Behlouli H & 31 \\
\hline Bergeron J & 19 \\
\hline Bernatsky S & $29,32,33$ \\
\hline Binder L & 10 \\
\hline Blackburn D & 7 \\
\hline Blouin J & 21 \\
\hline Boire G & 32 \\
\hline Bombardier C & $5,6,13$ \\
\hline Bouchard S & 11 \\
\hline Bowles SK & 1 \\
\hline Brisson C & 14 \\
\hline Brown KJ & 18 \\
\hline Burden AM & 20 \\
\hline Bykerk VP & 32 \\
\hline Cadarette SM & $18,20,40$ \\
\hline Cesta A & $5,6,13$ \\
\hline Chan AW & 29 \\
\hline Chan K & 29 \\
\hline Chattha M & 39 \\
\hline Cheema P & 11 \\
\hline Cheung AM & 18,20 \\
\hline Cheung W & 11 \\
\hline Choiniere M & 16,19 \\
\hline Chong SG & 36 \\
\hline & \\
\hline
\end{tabular}

\begin{tabular}{|c|c|}
\hline Choquette D & 32 \\
\hline Chow G & 39 \\
\hline Clarke $\mathrm{AE}$ & 33 \\
\hline Colmegna I & 29 \\
\hline Coupal L & 32 \\
\hline Cox G & 36 \\
\hline Curtis JR & 29 \\
\hline Dalseg C & 17 \\
\hline Dassieu L & 16 \\
\hline De Jaray A & 17 \\
\hline Dolovich L & 28,40 \\
\hline Doobay J & 24 \\
\hline Dube M & $3,4,19$ \\
\hline Edwin JJ & 34,35 \\
\hline Elnoursi A & 34,35 \\
\hline Evans C & 7,30 \\
\hline Farooqi M & 36 \\
\hline Fauteux C & 16 \\
\hline Feeny D & 8 \\
\hline Fisk JD & 30 \\
\hline Forte L & 39 \\
\hline Forte M & 39 \\
\hline Fortin PR & 33 \\
\hline Gamble JM & 40 \\
\hline Gaudet D & 19 \\
\hline Giacomantonio N & 15 \\
\hline Gilbert-Ouimet M & 14 \\
\hline Glennie J & 11 \\
\hline Godbout-Parent M & 16 \\
\hline Gomes T & 23 \\
\hline Gosselin E & 3 \\
\hline Grootendorst P & 20 \\
\hline Guertin JR & 8,14 \\
\hline Hambly N & 36 \\
\hline Hanly JG & 33 \\
\hline Hassan S & 34,35 \\
\hline Hayes J & 24 \\
\hline Hayes KN & 18 \\
\hline $\mathrm{He} \mathrm{N}$ & 18,20 \\
\hline Henricks P & 26 \\
\hline Hepworth E & 13 \\
\hline Hiller TWR & 15 \\
\hline Holbrook A & 27,28 \\
\hline Huang A & 10 \\
\hline Hudson M & 29 \\
\hline
\end{tabular}

J Popul Ther Clin Pharmacol Vol 27(4):e19-e54; December 1, 2020.

This article is distributed under the terms of the Creative CommonsAttribution-Non Commercial 4.0 International License. 


\begin{tabular}{|c|c|}
\hline Hudspith M & 16 \\
\hline Humphries B & 8,26 \\
\hline Hurry M & 34,35 \\
\hline Isitt JJ & 41 \\
\hline Jamal R & 29 \\
\hline $\begin{array}{l}\text { Janelle-Montcalm } \\
\text { A }\end{array}$ & 16 \\
\hline Jeffery $\mathbf{w}$ & 39 \\
\hline Johnson SMA & 19 \\
\hline Juurlink DN & 18 \\
\hline Kim S & 20 \\
\hline Kingwell E & 30 \\
\hline Kirkland S & 1 \\
\hline Kirwin E & 25 \\
\hline Kolb M & 36 \\
\hline Konstantelos N & 20 \\
\hline Kurteva S & 23 \\
\hline Lacasse A & 16 \\
\hline Lal A & 21 \\
\hline Laliberte $\mathrm{J}$ & 16 \\
\hline Lamb-Palmer D & 26 \\
\hline Lanctat $\mathrm{H}$ & 19 \\
\hline Langevin C & 12 \\
\hline Lavoie R & 9 \\
\hline Lech R & 39 \\
\hline Lee J & 28 \\
\hline Lelorier J & 19 \\
\hline Li X & 5,6 \\
\hline Liu J & 38 \\
\hline Lix L & 7 \\
\hline Lu A & 21 \\
\hline Lunghi C & 2 \\
\hline Lynch P & 41 \\
\hline MacCallum L & 40 \\
\hline Machado MAA & 29 \\
\hline Maier-Downing T & 38 \\
\hline Maksymowych WP & 32 \\
\hline Malmberg C & 39 \\
\hline Mann K & 39 \\
\hline Marino JP & 22 \\
\hline Marrie RA & 30 \\
\hline McCabe C & 25 \\
\hline Milenkovski R & 22 \\
\hline Mintzes BJ & 37 \\
\hline Miregwa B & 27 \\
\hline
\end{tabular}

\begin{tabular}{|l|l|}
\hline Mirza R & 13 \\
\hline Moor G & 16 \\
\hline Morrow RL & 37 \\
\hline Moura CS & 29,32 \\
\hline Movahedi M & $5,6,13$ \\
\hline Ng HS & 30 \\
\hline Nguena Nguefack & 16 \\
HL & \\
\hline Nguyen S & 24 \\
\hline OReilly DJ & 9 \\
\hline Ouali A & 2 \\
\hline Page MG & 16 \\
\hline Penner N & 21 \\
\hline Peschken CA & 33 \\
\hline Peters R & 28 \\
\hline Pilote L & 29,31 \\
\hline Pineau CA & 33 \\
\hline Rafferty E & 25 \\
\hline Rochette L & 2 \\
\hline Round J & 25 \\
\hline Roze S & 41 \\
\hline Sakkat A & 36 \\
\hline Scallan C & 36 \\
\hline Scheider KAB & 34,35 \\
\hline Schieir O & 32 \\
\hline Seung SJ & 34,35 \\
\hline Shakeri A & 40 \\
\hline Simard M & 3,4 \\
\hline Sirois C & $2,3,4$ \\
\hline Smith-Palmer J & 41 \\
\hline Soares de Moura C & 31 \\
\hline Sohani Z & 31 \\
\hline Stein B & 11 \\
\hline Sultan-Taieb H & 14 \\
\hline Sutton K & 16 \\
\hline Svenson L & 30 \\
\hline Sze F & 17 \\
\hline Tamblyn R & 23 \\
\hline Tardif JC & 19 \\
\hline Tarride JE & 8 \\
\hline Teare G & 7 \\
\hline Thompson J & 16 \\
\hline Tong R & 10 \\
\hline Tremlett H & 30 \\
\hline Trenaman SC & 1 \\
\hline & \\
\hline & \\
\hline
\end{tabular}

J Popul Ther Clin Pharmacol Vol 27(4):e19-e54; December 1, 2020.

This article is distributed under the terms of the Creative CommonsAttribution-Non Commercial 4.0 International License. (C) 2020 CAPT. 


\begin{tabular}{|l|l|}
\hline Turnbull G & 17 \\
\hline Valois MF & 32 \\
\hline Vinet E & 33 \\
\hline Walton RN & 34,35 \\
\hline Wilhelm L & 16 \\
\hline Wills A & 17 \\
\hline Wongkarnjama A & 36 \\
\hline Yao S & 7 \\
\hline Zhang J & 28 \\
\hline Zhao Y & 30 \\
\hline Zhu F & 30 \\
\hline
\end{tabular}

J Popul Ther Clin Pharmacol Vol 27(4):e19-e54; December 1, 2020.

This article is distributed under the terms of the Creative CommonsAttribution-Non Commercial 4.0 International License. (C) 2020 CAPT. 